\title{
Pregnancy Intention and Pregnancy Outcome: Systematic Review and Meta-Analysis
}

\author{
Jennifer A. Hall ${ }^{1} \cdot$ Lorna Benton $^{2} \cdot$ Andrew Copas $^{3} \cdot$ Judith Stephenson $^{1}$
}

Published online: 16 January 2017

(C) The Author(s) 2017. This article is published with open access at Springerlink.com

\begin{abstract}
Introduction Previous systematic reviews concluded that rigorous research on the relationships between pregnancy intentions and pregnancy outcomes is limited. They further noted that most studies were conducted in high-income countries and had methodological limitations. We aim to assess the current evidence base for the relationship between pregnancy intention and miscarriage, stillbirth, low birthweight (LBW) and neonatal mortality. In March 2015 Embase, PubMed, Scopus and PsychInfo were searched for studies investigating the relationship between pregnancy intention and the outcomes of interest. Methods Studies published since 1975 and in English, French or Spanish were included. Two reviewers screened titles and abstracts, read the full text of identified articles and extracted data. Meta-analyses were conducted where possible. Results Thirty-seven studies assessing the relationships between pregnancy intention and LBW were identified. A meta-analysis of 17 of these studies found that unintended pregnancies are associated with 1.41 times greater odds
\end{abstract}

Jennifer A. Hall

jennifer.hall@ucl.ac.uk

Lorna Benton

lorna.benton.09@ucl.ac.uk

Andrew Copas

a.copas@ucl.ac.uk

Judith Stephenson

judith.stephenson@ucl.ac.uk

1 Research Department of Reproductive Health, UCL Institute for Women's Health, London, UK

2 Department of Population Policy and Practice, UCL Institute of Child Health, London, UK

3 Department of Infection and Population Health, UCL Institute of Epidemiology and Health Care, London, UK of having a LBW baby (95\%CI 1.31, 1.51). Eight studies looking at miscarriage, stillbirth or neonatal death were found. The limited data concerning pregnancy loss and neonatal mortality precluded meta-analysis but suggest these outcomes may be more common in unintended pregnancies. Discussion While there seems to be an increased risk of adverse pregnancy outcome in unintended pregnancies, there has been little improvement in either the quantity of evidence from low-income countries or in the quality of evidence generally. Longitudinal studies of pregnancy intention and pregnancy outcome, where pregnancy intention is assessed prospectively with a validated measure and where analyses include confounding or mediating factors, are required in both high- and low-income countries.

Keywords Systematic review $\cdot$ Meta-analysis $\cdot$ Pregnancy intention · Miscarriage $\cdot$ Stillbirth $\cdot$ Low birthweight .

Neonatal mortality

\section{Significance}

What is already known on this subject? Pregnancy intention may be associated with adverse pregnancy outcomes. Previous systematic reviews concluded that insufficient attention has been paid to investigating these relationships. They further noted that most studies were conducted in high-income countries and had methodological limitations that could invalidate their findings.

What this study adds? This review provides an updated meta-analysis of the relationship between pregnancy intention and LBW. In addition persistent gaps and flaws in the literature are demonstrated. Retrospective, cross-sectional studies predominate, despite their limitations. Longitudinal studies with analyses that 
include confounding or mediating factors are required in both high- and low-income countries.

\section{Background}

It may seem self-evident that unintended pregnancies would be associated with adverse outcomes. However, the evidence base for the relationships between pregnancy intention and maternal and neonatal outcomes is mixed. Between 2008 and 2011 there were three systematic reviews published on this topic (Gipson et al. 2008; Shah et al. 2011; Tsui et al. 2010). These reviews concluded that scant attention had been paid to investigating the relationships between pregnancy intention, health behaviours and maternal and child health outcomes, that the existing research was 'older and methodologically limited' (p157) (Tsui et al. 2010) and that there are 'persistent gaps in the literature, indicating a need for more studies in developing countries' (p18) (Gipson et al. 2008).

Only Shah et al. (2011) conducted a meta-analysis, calculating a crude odds ratio (OR) for unintended pregnancies of 1.36 (95\% confidence interval $(95 \% \mathrm{CI}) 1.25$, 1.48) for low birthweight (LBW) and 1.31 (95\% CI 1.09, 1.58) for preterm birth (PTB). The meta-analysis was conducted on unadjusted estimates, given the variation in confounders adjusted for by different studies, and may therefore overestimate the relationship. Almost all studies were conducted in Europe or the USA meaning these findings may not have relevance to low-income countries (LICs). Moreover most studies were retrospective, crosssectional surveys using a single question to dichotomise pregnancies into intended and unintended. These are the methodological limitations referred to by Tsui et al. (2010) because they over-simplify the complex construct of pregnancy intention, resulting in misclassification bias, and introduce recall bias given the time elapsed between the pregnancy and the timing of assessment (up to 5 years after birth). The temporal separation between pregnancy intention and outcome is lost making any assessment of mechanism of effect, or cause and effect, impossible.

Five years on this systematic review aims to assess the current evidence base for the relationships between pregnancy intention and adverse pregnancy outcomes. In addition to LBW we review the evidence for miscarriage, stillbirth and neonatal mortality, conducting metaanalyses where possible and comparing findings for LICs and high-income countries (HICs).

\section{Methodology}

\section{Search Strategy and Keywords}

The literature review and meta-analyses were conducted in line with the 'Meta-analysis of Observational Studies in Epidemiology (MOOSE)' guidelines (Stroup et al. 2000). Searches were carried out on the electronic databases Embase, PubMed and Scopus in March 2015. Where possible Medical Subject Headings were used. For unintended pregnancy, the exposure, stems and words covering the concepts of pregnancy, fertility, birth, child, intention, want, planning or timing were used and were combined using the Boolean operator 'or'.

Definitions of the outcomes are shown in Box 1. For the outcomes, full and truncated terms, acronyms e.g. LBW for low birthweight, synonyms such as neonatal death and neonatal mortality, and the generic 'pregnancy outcome' were combined with 'or'. The results of the separate pregnancy intention and outcome searches were then combined with 'and'. The search also included the outcome of postnatal depression and was additionally conducted on PsychInfo. The findings of the relationship between pregnancy intention and postnatal depression are presented elsewhere.

Box 1 Definitions of outcomes of interest

\begin{tabular}{lc}
\hline Miscarriage & $\begin{array}{c}\text { A pregnancy lost before } 28 \text { weeks' } \\
\text { gestation } \\
\text { A baby born with no signs of life } \\
\text { at or after } 28 \text { weeks' gestation }\end{array}$ \\
Low birthweight & $\begin{array}{c}\text { A baby born weighing }<2500 \mathrm{~g} \\
\text { regardless of gestation }\end{array}$ \\
Neonatal death & $\begin{array}{c}\text { A baby born alive but who dies } \\
\text { within the first } 28 \text { days of life }\end{array}$ \\
\hline
\end{tabular}

\section{Inclusion and Exclusion Criteria}

Observational studies of any design that investigated the relationship between pregnancy intention and at least one of the outcomes of interest were eligible for inclusion in the review. Studies in restricted populations, such as teenagers or those with particular medical conditions, were excluded, as these were not representative of the general population. Sufficient information on how pregnancy intention was assessed and reported had to be provided, but no restrictions were placed on the timing or method of the assessment. Articles published since 1975 and in English, French or Spanish were eligible for inclusion.

$\mathrm{JH}$ and LB reviewed the titles and abstracts independently. All abstracts selected by either reviewer were 
retained for full-text review. The references of these articles were also reviewed to identify any additional eligible studies.

\section{Quality of Study and Risk of Bias}

The potential sources of bias by which the studies were assessed included how the sample was selected, whether the sample was representative, sample size, how the exposure and outcomes were measured (whether they were validated measures and the timing of the assessment), confounders that were controlled for, loss to follow-up and the type of analysis conducted. Where appropriate funnel plots were created to investigate publication bias and/or small study effects.

\section{Data Extraction}

Data were extracted from the studies independently by $\mathrm{JH}$ and LB, using a template designed for this review, and differences resolved by discussion. Data extracted included the location, population, measure and timing of pregnancy intention, proportion of pregnancies classed as unintended (and mistimed or ambivalent if presented), method of assessing the outcome, outcome data and confounders controlled for.

\section{Meta-Analysis}

Where there were sufficient studies with data available for the primary outcomes, raw data were extracted from the papers and meta-analyses conducted in Stata to calculate an overall effect size estimate (odds ratio) for the studies. Heterogeneity between studies was assessed before deciding whether to conduct a fixed-effects or random-effects analysis. Given the expected variety of study populations, study design and assessment method it was decided a priori to stratify the analysis by location (using World Bank country classifications) and whether pregnancy intention was assessed during pregnancy or afterwards.

\section{Results}

\section{Search Results}

The four database searches looking at all outcomes returned a total of 3159 hits combined. 945 of these were duplicates, 40 were excluded as they were pre-1975 and 117 on the basis of language. Following review of the title and abstract 1973 were removed, mostly because they were not addressing the relationship between pregnancy intention and an outcome of interest.
There were 84 studies relevant to the primary outcomes: eight to miscarriage, stillbirth or neonatal death, 28 to low birthweight and 48 to postnatal depression. The flowchart for the literature review is shown in Fig. 1.

\section{Pregnancy Intention and Miscarriage, Stillbirth or Neonatal Death}

Eight studies that addressed the relationships between pregnancy intention and miscarriage, stillbirth or neonatal death were identified from the literature review. One was excluded on full text review as it contained no data and an additional study was identified from the references of other papers, giving eight studies in total. The characteristics of these studies are included in Table 1.

\section{Pregnancy Intention and Miscarriage or Stillbirth}

There are very few data on the relationship between pregnancy intention and miscarriage or stillbirth; just two studies in a HIC and one in a LIC. Dawen et al. found no relationship between unintended pregnancy and miscarriage in women attending an early pregnancy unit in London, UK (Dawen et al. 2014). Using the London Measure of Unplanned Pregnancy (LMUP) in the UK, Wellings et al. (2013) noted that unplanned pregnancies were more likely to end in abortion, but there was no difference in the proportion ending in miscarriage.

A study in Ethiopia identified pregnant women in the community, assessed their pregnancy intention and followed them up monthly until the outcome of the pregnancy was known (Assefa et al. 2012). Miscarriage, induced abortion and stillbirth were analysed as a composite of 'pregnancy loss'. Using a robust, prospective methodology they found an adjusted hazard ratio for pregnancy loss of 2.2 $(95 \%$ CI $1.56,3.11)$ for unintended compared to intended pregnancies.

\section{Pregnancy Intention and Neonatal Mortality}

There have been more studies looking at neonatal mortality in both HICs and LICs. Two studies in the USA found that unintended pregnancies had a greater risk of neonatal mortality. In California, Laukaran and van den Berg (1980) found a relative risk (RR) of perinatal mortality of 1.80 $(p=0.003)$ (adjusted for parity and husband's occupation). ${ }^{1}$ Bustan and Coker (1994) found an adjusted RR of 2.4 $(95 \%$ CI $1.5,4.0)$ for neonatal mortality in married women with health insurance who received early antenatal care but

\footnotetext{
1 They defined perinatal mortality as deaths from 4 months of pregnancy to 28 days after birth.
} 
Fig. 1 Flow chart of selection of studies for the literature review

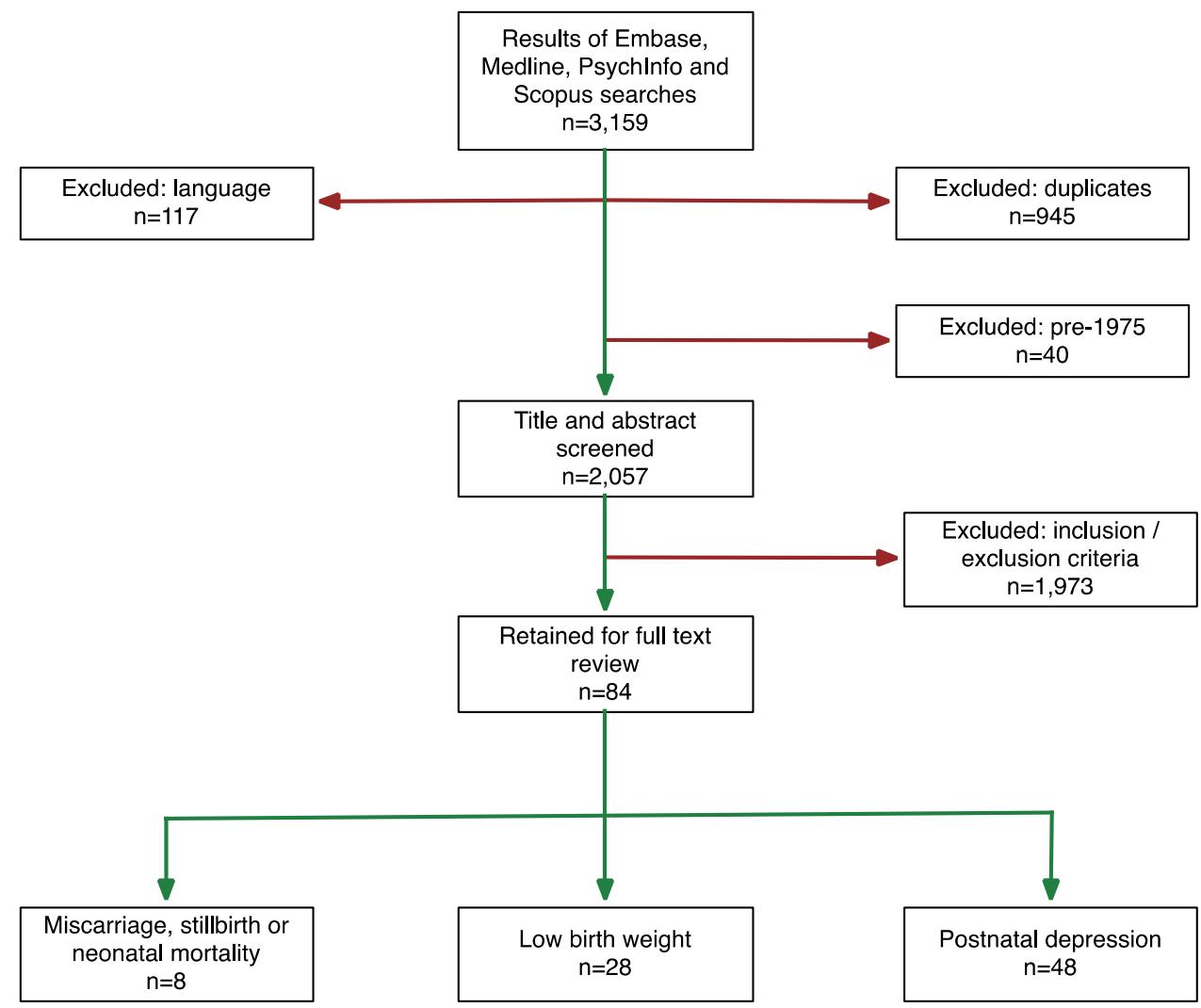

who felt negative about their pregnancies during pregnancy. The fact that an increased risk of mortality was found in these two low-risk populations is noteworthy. However, these studies are both old (data were collected in the 1950s and 60s) and their current applicability may be limited given changes in mortality rates and the availability of abortion since these data were collected.

Three studies in LICs looked at neonatal mortality; two from India (Singh et al. 2012; Singh and Mahapatra 2013) and one from Bangladesh (Chalansani et al. 2007). All three studies found increased risk of neonatal mortality, as shown Table 2. Singh and Mahapatra (2013) and Chalansani et al. (2007) both used prospective fertility intentions and used siblings to control for unobserved heterogeneity at the level of the family, making these studies particularly robust.

\section{Pregnancy Intention and Low Birthweight}

The search identified 28 studies potentially relating to pregnancy intention and low birthweight after title and abstract screening; a further nine were added from reference searches. The characteristics of these 37 studies are shown in Table 3.

In brief, 27 of these studies were from HICs, two were from LICs (Ethiopia and Benin), two from lower-middleincome countries (LMICs) (one each from Ghana and
Egypt), four from upper-middle-income countries (UMICs) (three from Iran and one from Ecuador) and two presented data from several countries.

To assess pregnancy intention, the USA studies tended to use either the National Survey of Family Growth or Pregnancy Risk Assessment Monitoring System questions; the studies in LICs were mostly based on the Demographic and Health Survey questions (see Appendix 1 for question wording). Questions about planning or wanting a pregnancy, attitude towards the pregnancy or about the timing of the pregnancy were all considered to be assessing pregnancy intention by these studies. However, these are different dimensions of the concept of pregnancy intention. Only seven had assessed intentions during pregnancy, the other 30 asked women any time from shortly after delivery to up to 5 years after the birth.

On full-text review 20 studies were excluded, as shown in Fig. 2, leaving 17 for inclusion in the meta-analysis.

\section{Description of Included Studies}

Of the 17 studies remaining, there were 14 from HICs, two from LICs and one from a LMIC (Ghana). Only two had assessed intentions during pregnancy and followed up women after birth (Fourn et al. 1999; Wado et al. 2014), the other 15 were retrospective, cross-sectional surveys. Study 


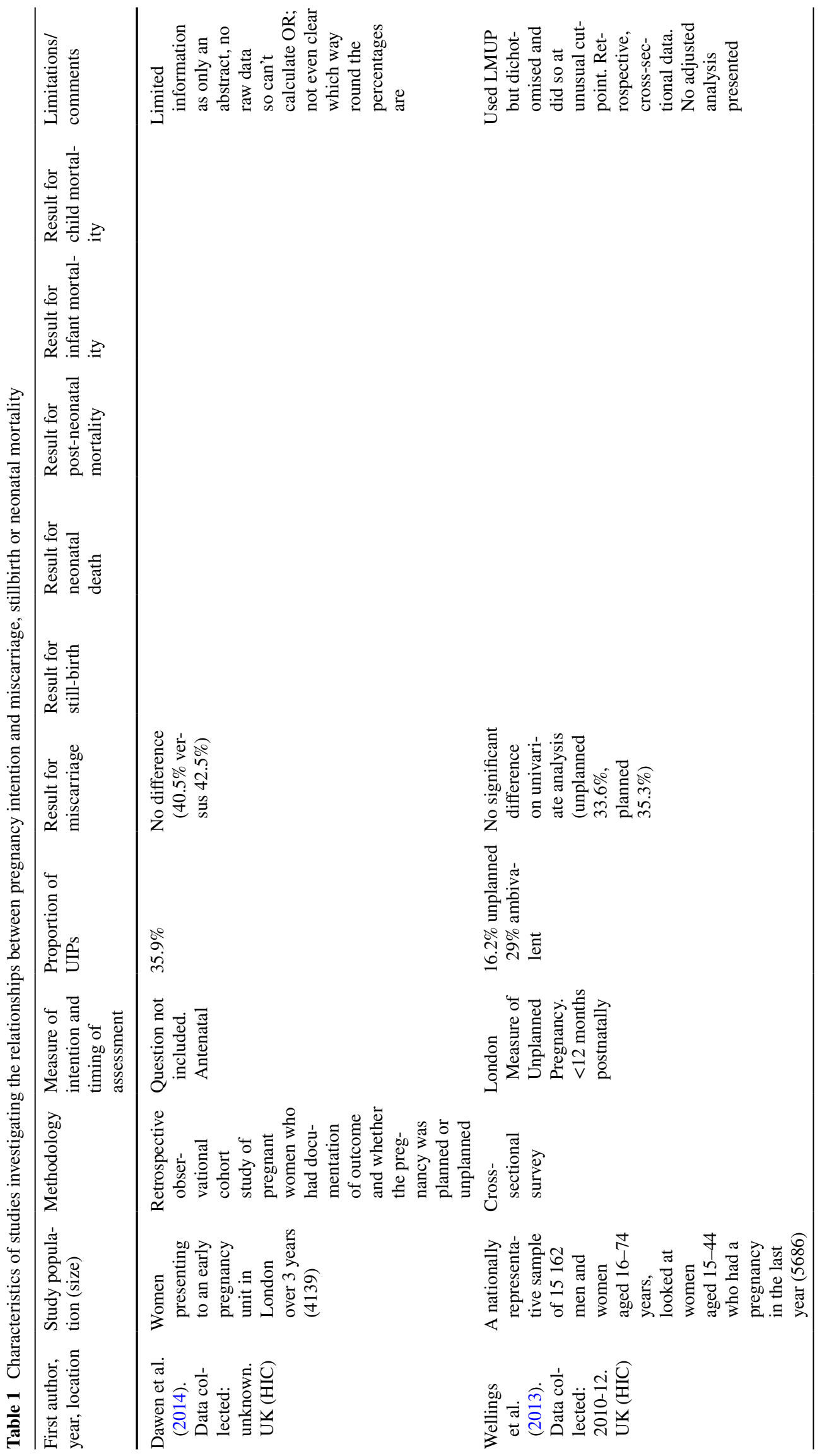




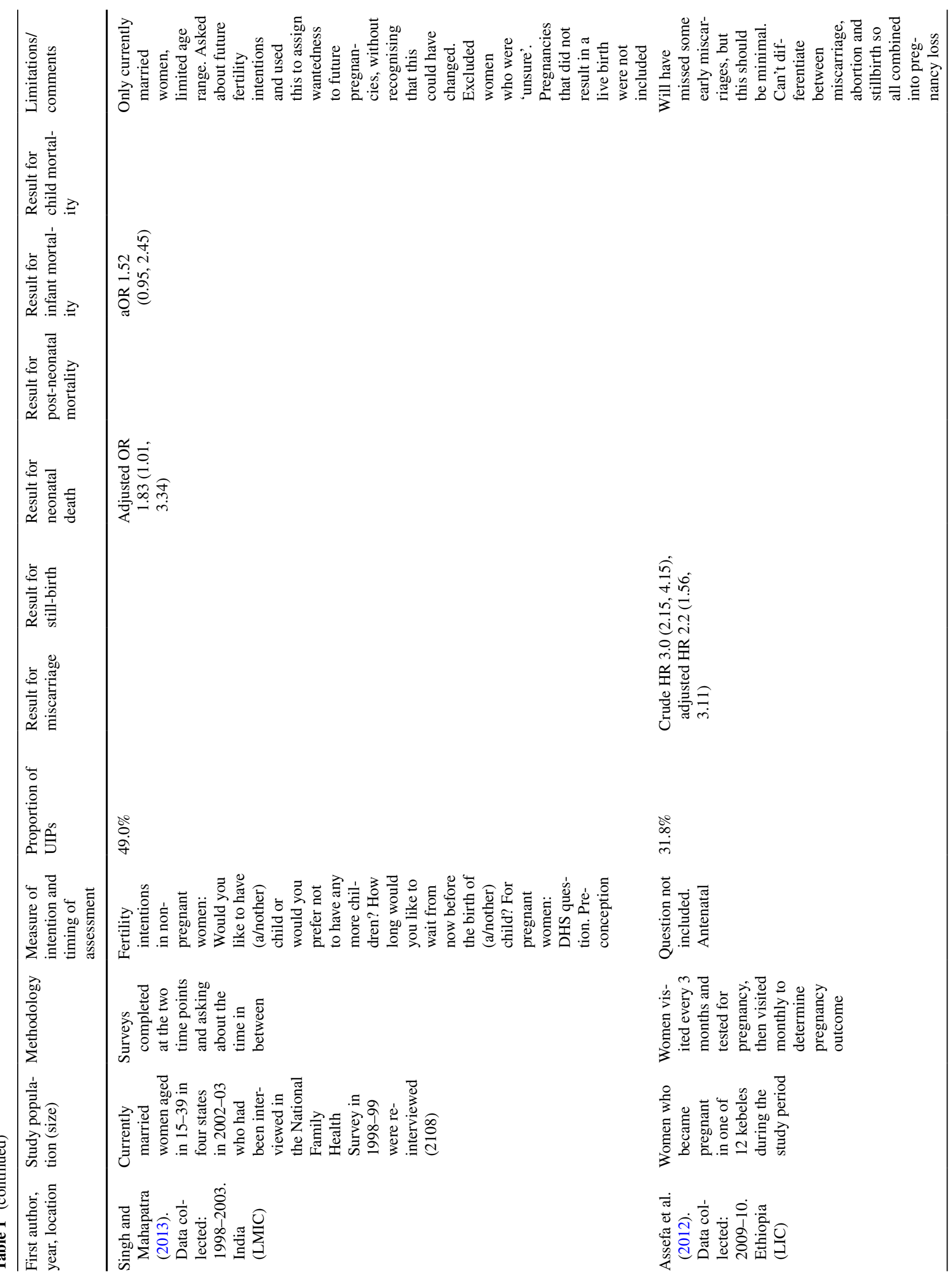




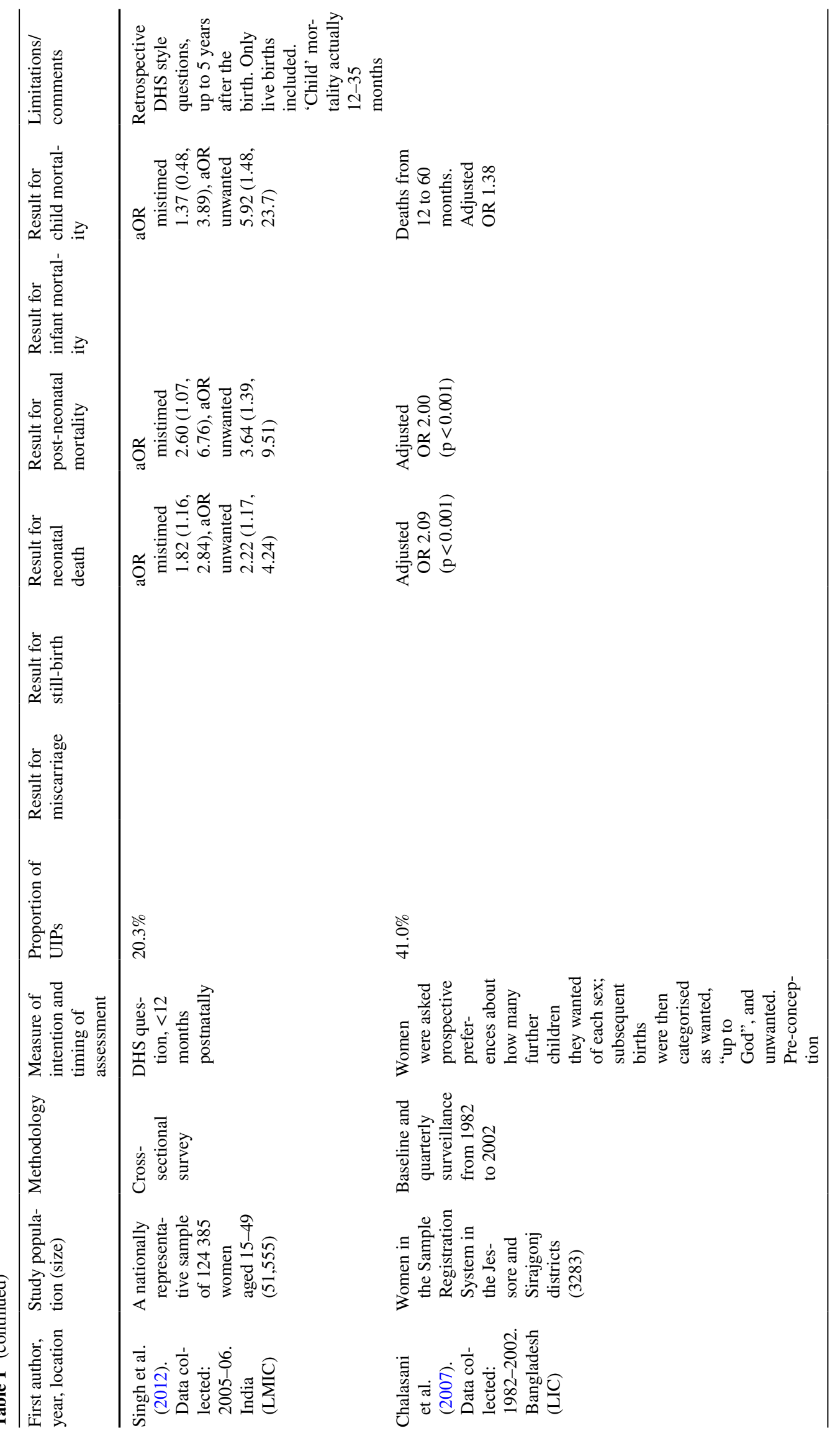




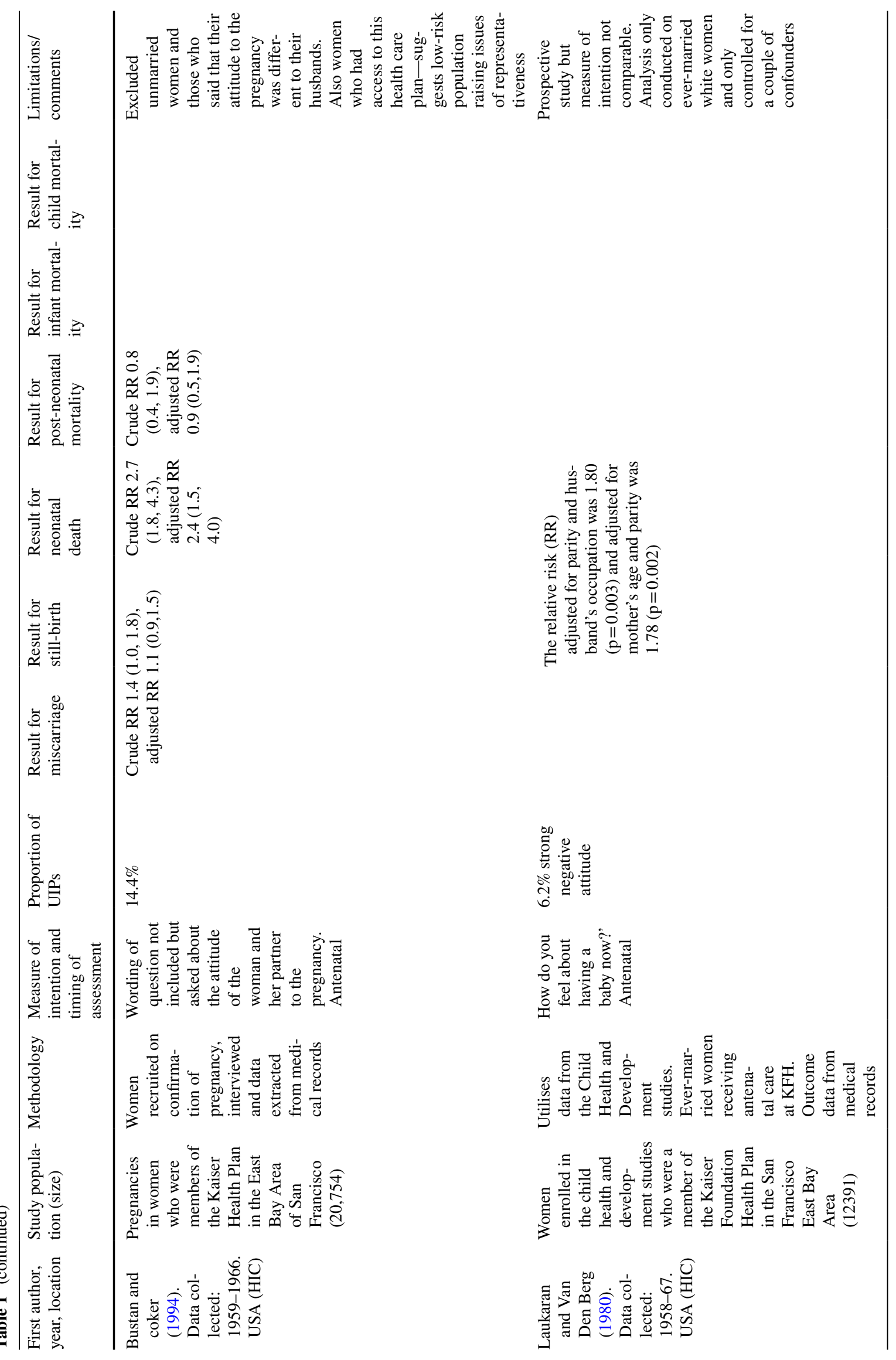


Table 2 Adjusted odds ratios and 95\%CI for pregnancy intention and neonatal mortality

\begin{tabular}{llll}
\hline Study & Neonatal mortality & Post-neonatal mortality & $\begin{array}{c}\text { Deaths from } 12 \\
\text { to } 35 \text { months }\end{array}$ \\
\hline $\begin{array}{l}\text { Singh et al. (2012), India } \\
\quad \text { Mistimed births }\end{array}$ & $1.82(1.16,2.84)$ & $2.06(1.07,6.76)$ & $1.37(0.48,3.89)$ \\
$\quad$ Unwanted births & $2.22(1.17,4.24)$ & $3.64(1.39,9.51)$ & $5.92(1.48,23.7)$ \\
Chalasani et al. (2007) & $2.09(\mathrm{p}<0.001)$ & $2.00(\mathrm{p}<0.001)$ & - \\
$\quad$ Unwanted births & Neonatal mortality & Infant mortality & - \\
\hline$\quad$ & & $1.52(0.95,2.45)$ \\
\hline Singh and Mahapatra (2013) & $1.83(1.01,3.34)$ & & \\
\hline
\end{tabular}

sample size ranged from just over 500-25,000 women as many were large, nationally representative surveys.

\section{Meta-Analyses of the Unadjusted Relationship}

Given the range of different confounders adjusted for in different studies, the raw data were first used to calculate unadjusted odds ratios for the meta-analysis, recognising that the apparent strength of association might be inflated by confounding. Given the significant and substantial heterogeneity between studies a random effects meta-analysis was performed as shown in Fig. 3.

This meta-analysis suggests that the odds of having a LBW baby are 1.41 times greater in women who have an unintended pregnancy $(95 \%$ CI $1.31,1.51)$. The heterogeneity seen may be a result of the range of locations or timing or method of assessment of pregnancy intention. Therefore separate meta-analyses were conducted stratified for these factors and are shown in Figs. 4 and 5.

Figure 4 shows that the two LIC studies had a significantly higher combined OR of 1.84 (95\%CI 1.52, 2.24) compared to $1.40(95 \%$ CI $1.30,1.50)$ in HIC countries. There was considerable heterogeneity between HIC countries. Figure 5 shows similar findings. Since the two antenatal studies were also the two studies in LICs it is not possible to say whether the higher pooled OR in these studies was due to the location or the timing of assessment. Theoretically speaking, the antenatal assessment of pregnancy intention should lead to a smaller effect size estimate as the potential for recall bias or for the outcome to influence the reported intention has been removed. On the other hand, the setting may lead to a larger effect size as the consequences of an unintended pregnancy may be more significant in a resource constrained environment.

\section{Findings of Adjusted Analyses}

Out of these 17 studies, six calculated aORs. Two studies found non-significant relationships after adjustment
(Lindberg et al. 2014; McCrory and McNally 2013). In two studies the findings remained significant with aORs of 1.60 (95\%CI 1.30, 2.0) (Fourn et al. 1999) and 1.24 (95\% CI 1.04, 1.48) (Flower et al. 2013). The final two studies had mixed findings. Wado et al. found that unwanted pregnancies remained significantly associated with LBW [aOR 2.08 (95\%CI 1.02, 4.23)] when compared with intended pregnancies, but mistimed pregnancies did not (Wado et al. 2014). Mohllajee et al., however, found that neither unwanted nor mistimed pregnancies had a relationship with LBW after adjusting for confounders, but women who were ambivalent had increased odds of LBW [aOR 1.15 (95\% CI 1.02, 1.29)] (Mohllajee et al. 2007). The fact that unintended pregnancies have been divided into different subcategories further complicates any comparison. Moreover, no two studies controlled for the same mix of confounders, which ranged from socio-demographic and obstetric history factors to smoking behaviour and uptake of antenatal care, which may be another explanation for these discrepancies.

\section{Publication Bias}

The funnel plot to check for publication bias or small study effects is shown in Fig. 6. The lack of studies in the bottom left hand corner indicates that smaller studies with negative findings are missing. This may be a consequence of publication bias or that stronger effects are seen in smaller studies perhaps because of different methodology.

\section{Discussion}

For LBW the meta-analyses of the unadjusted data suggest that unintended pregnancies (unwanted/mistimed/ambivalent combined) are associated with 1.41 times greater odds of having a low birthweight baby (95\% CI 1.31, 1.51) than an intended pregnancy. This is in keeping with the findings of the previous meta-analysis. This finding seems robust to the location of the study and the timing of the assessment 


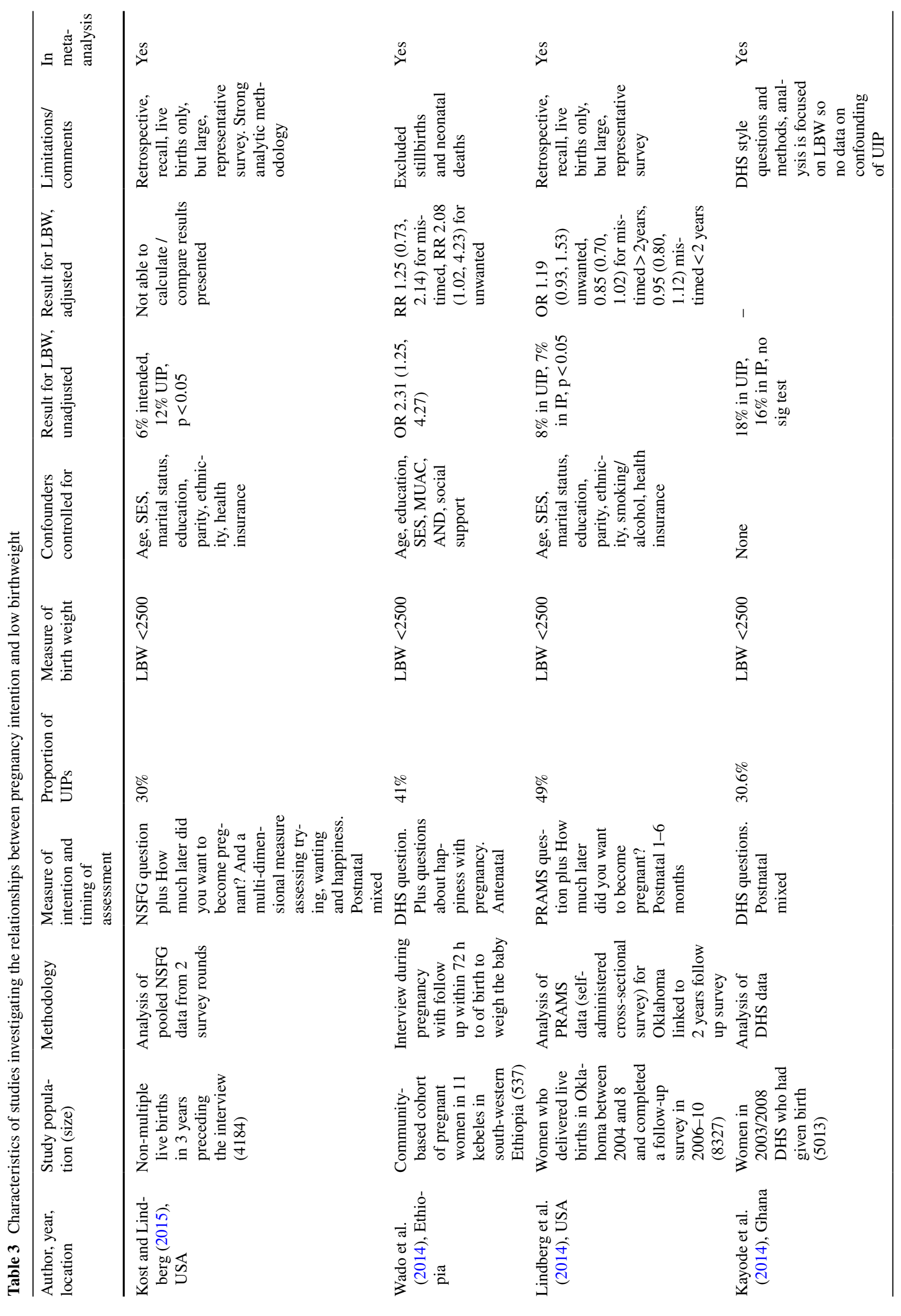




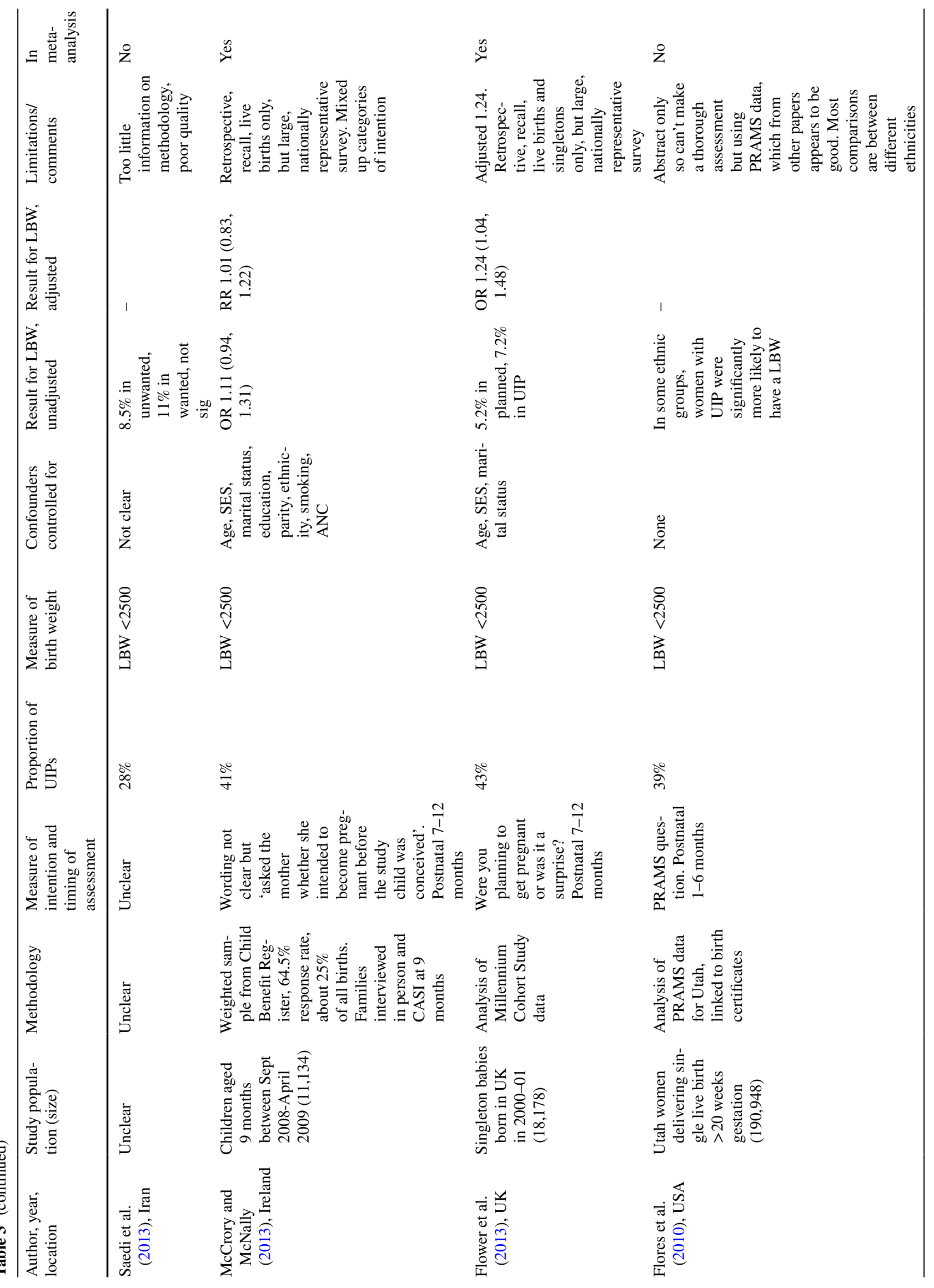




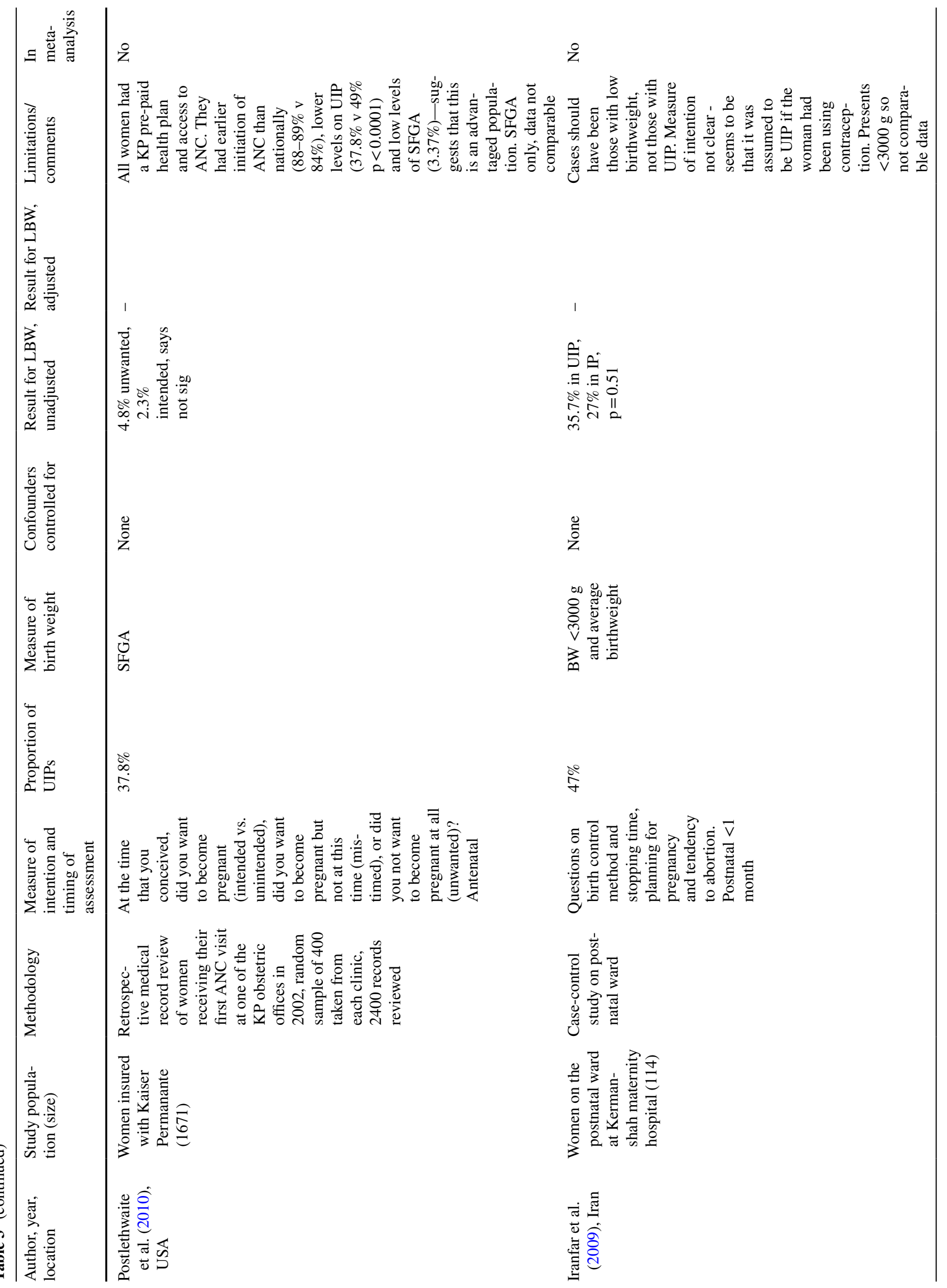




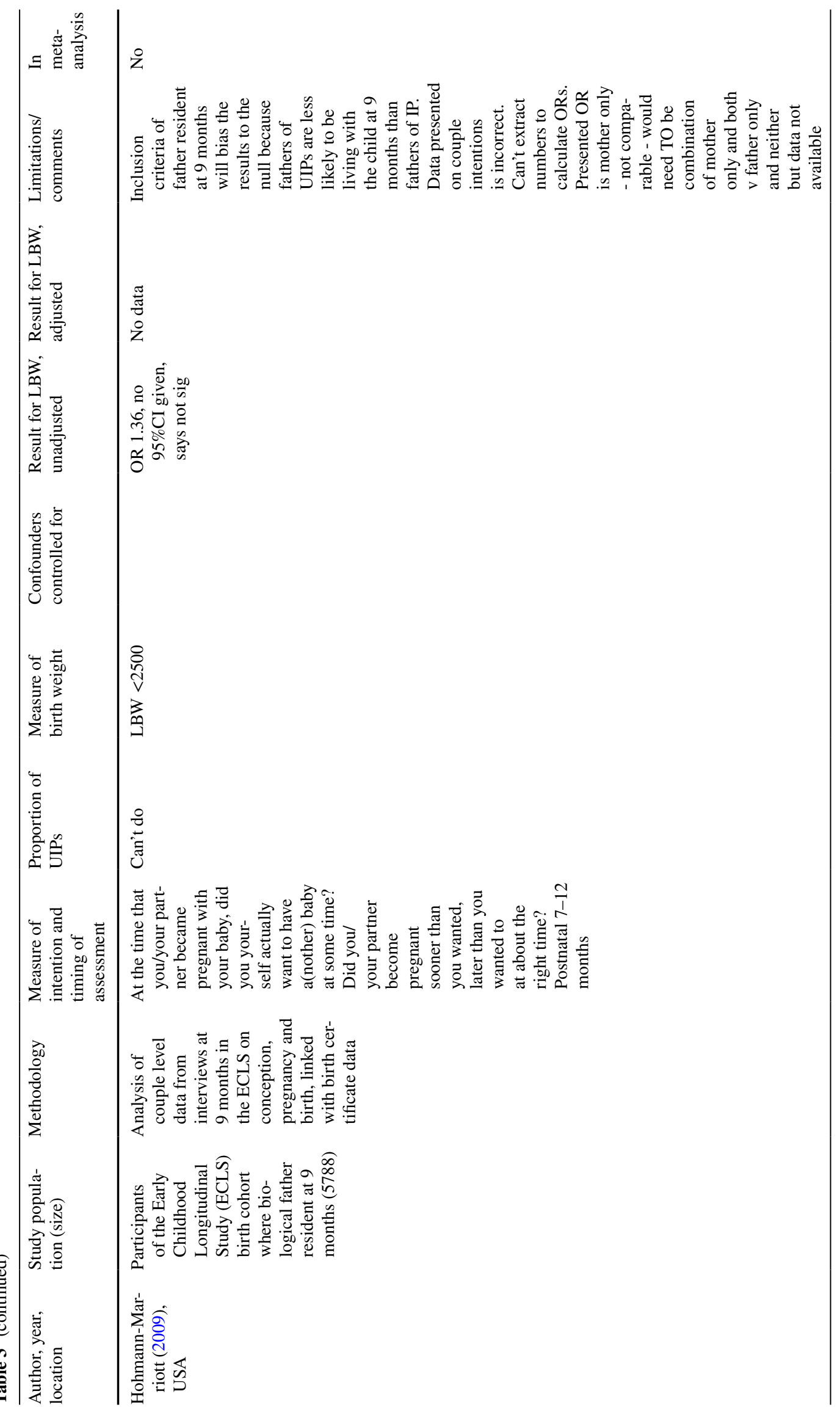




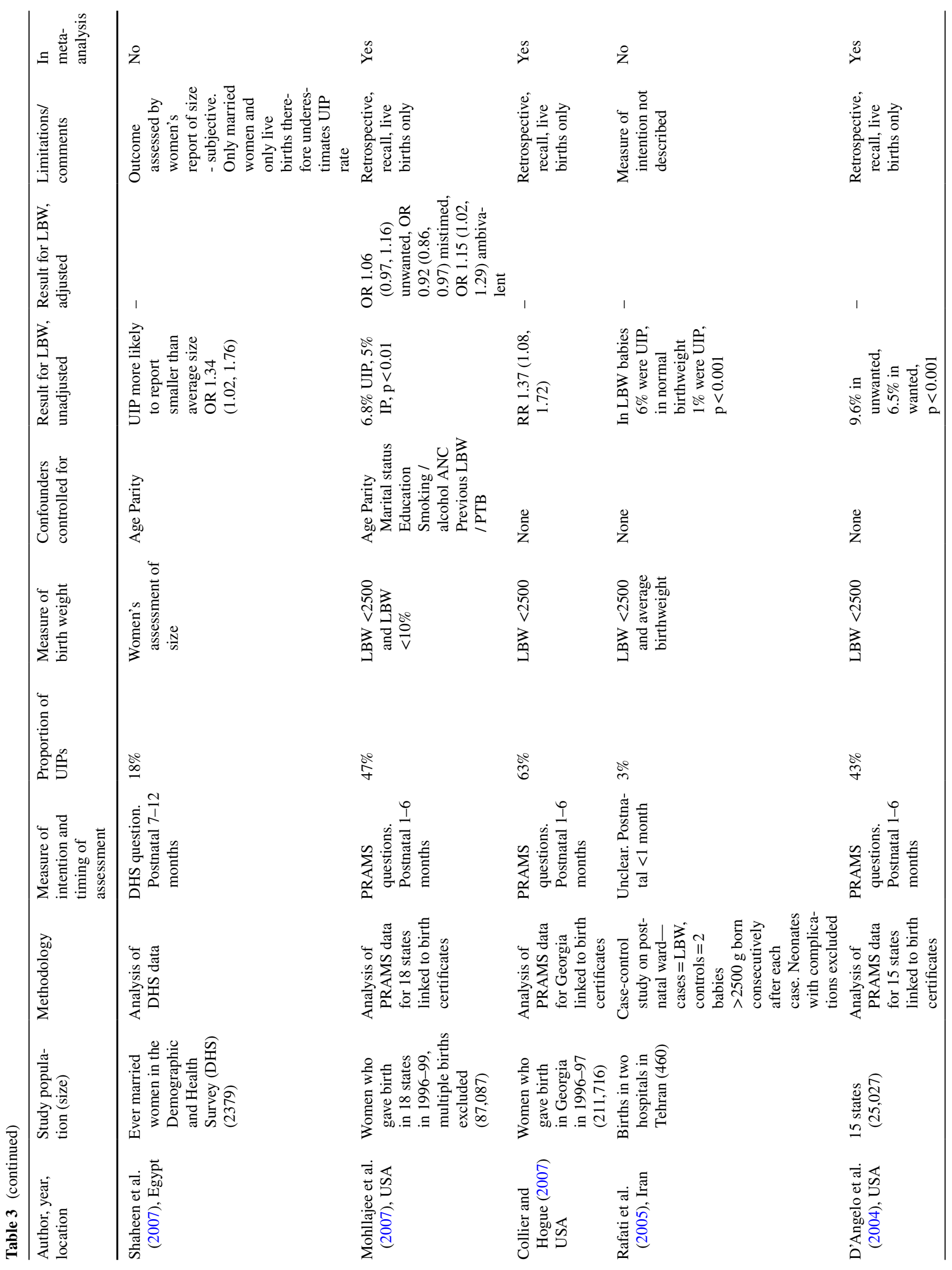




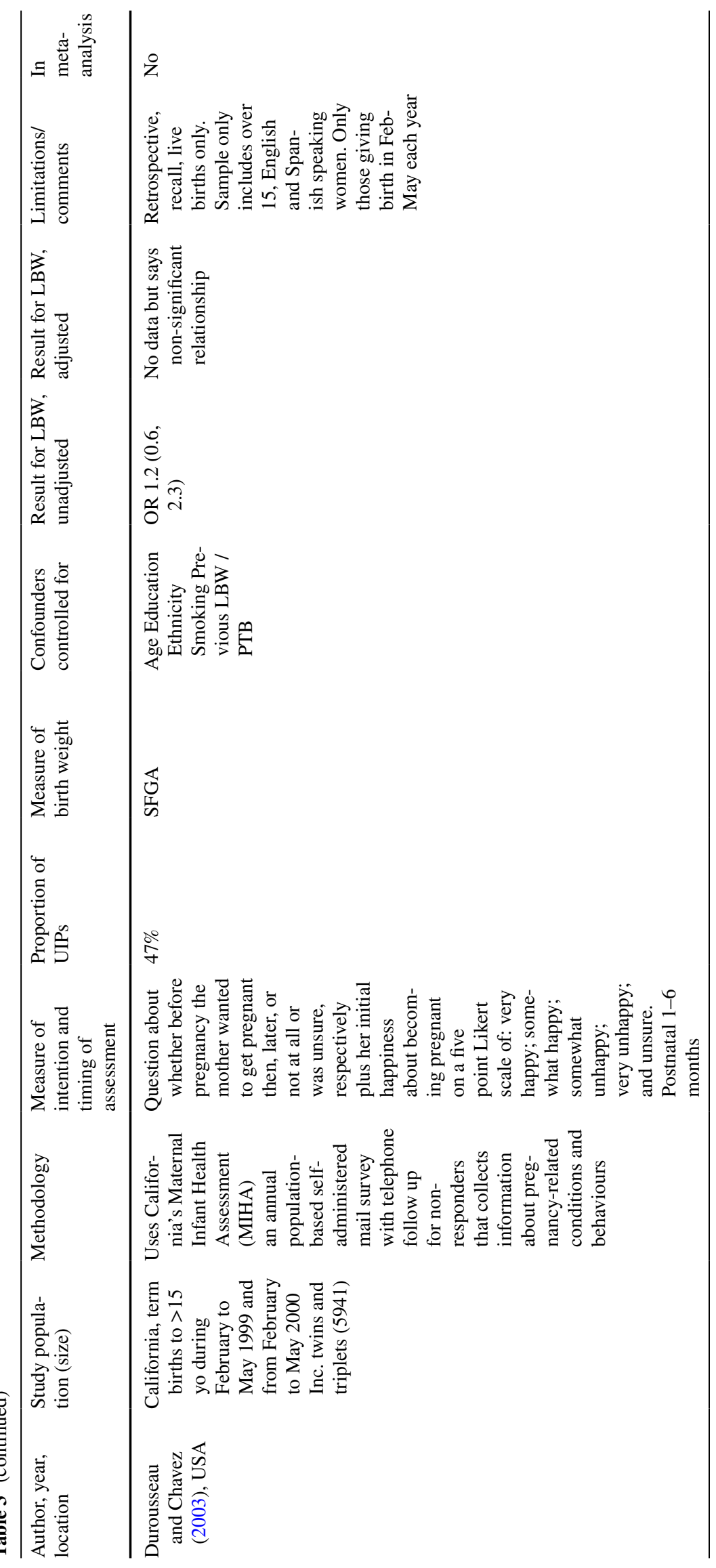




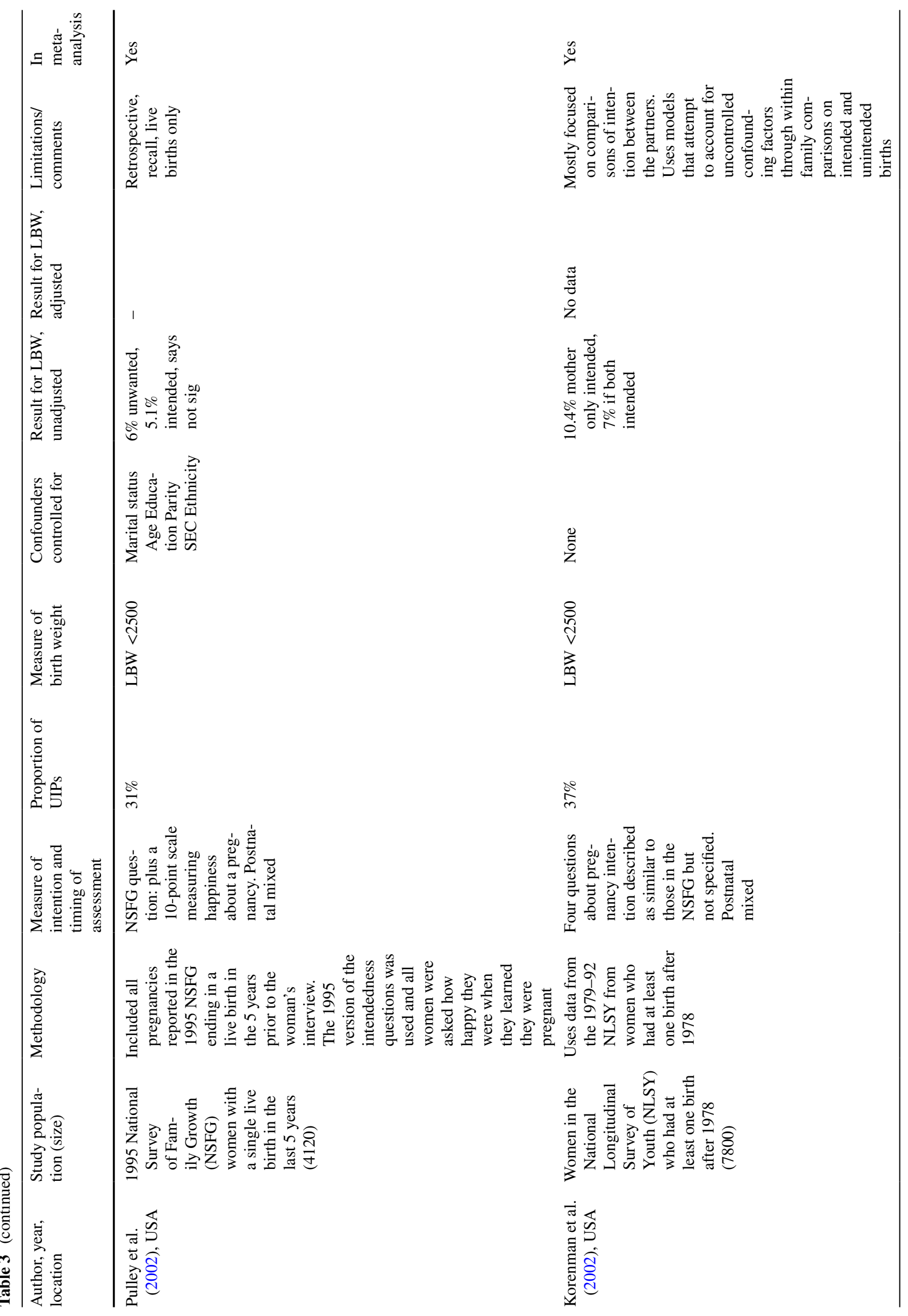




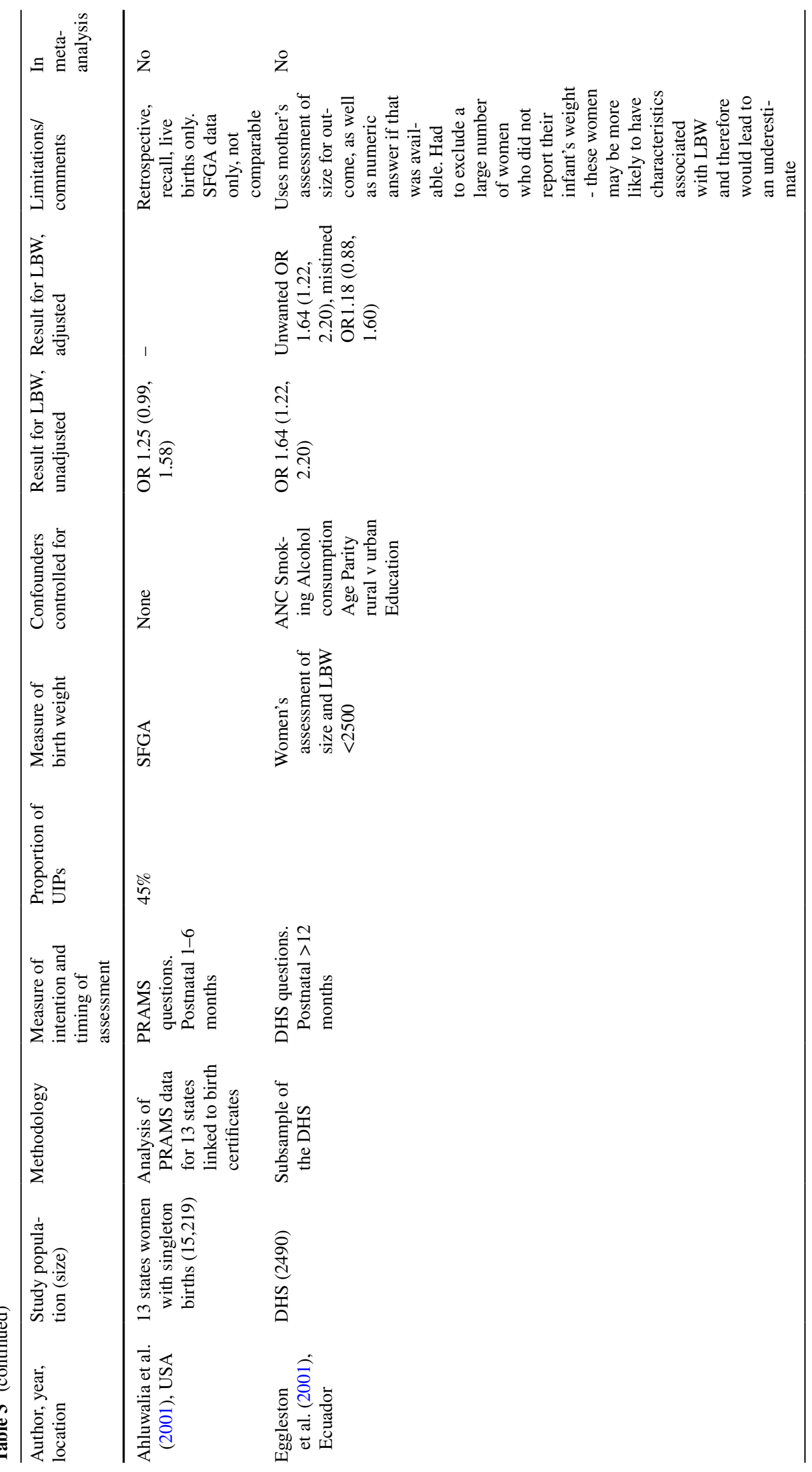




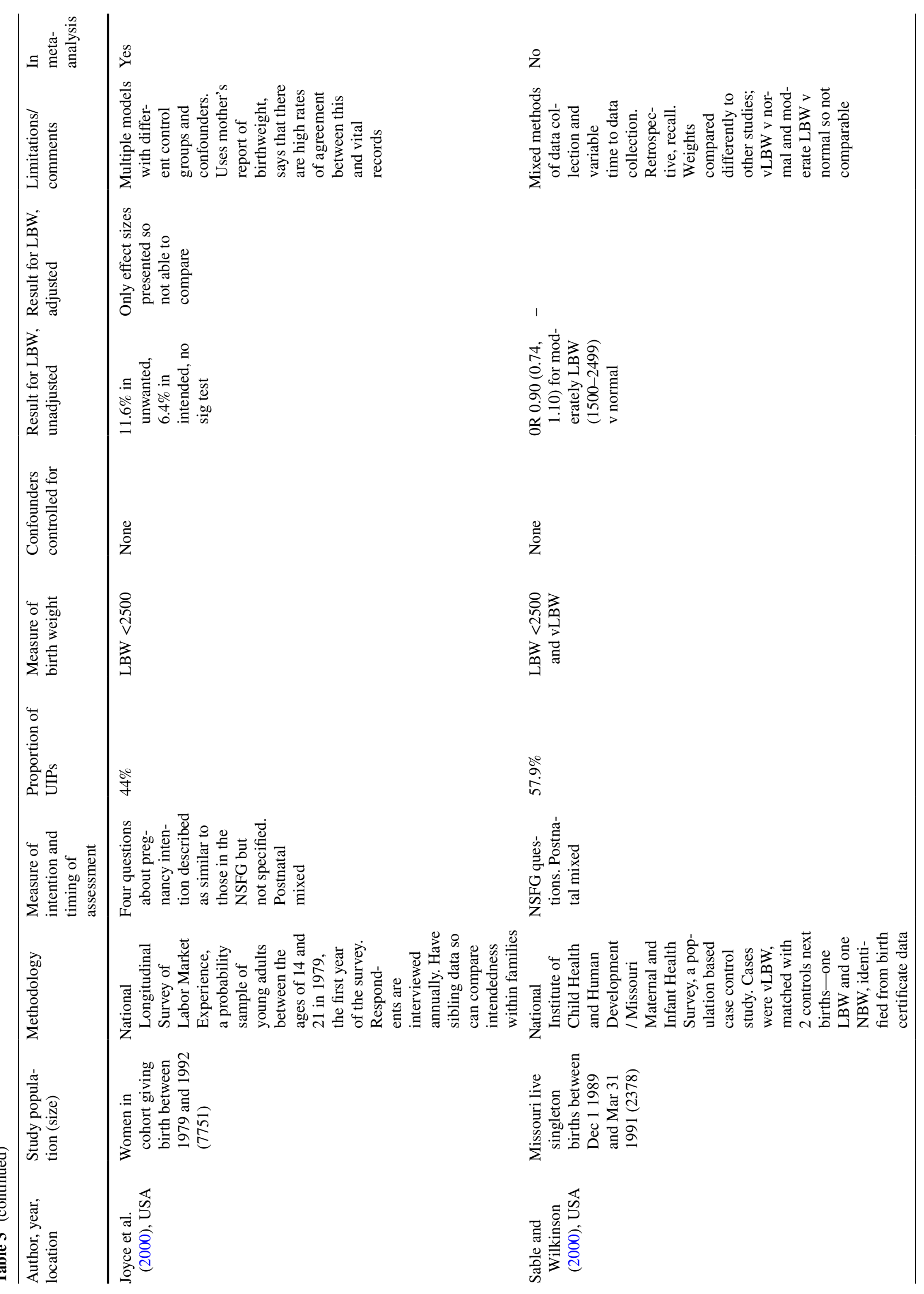




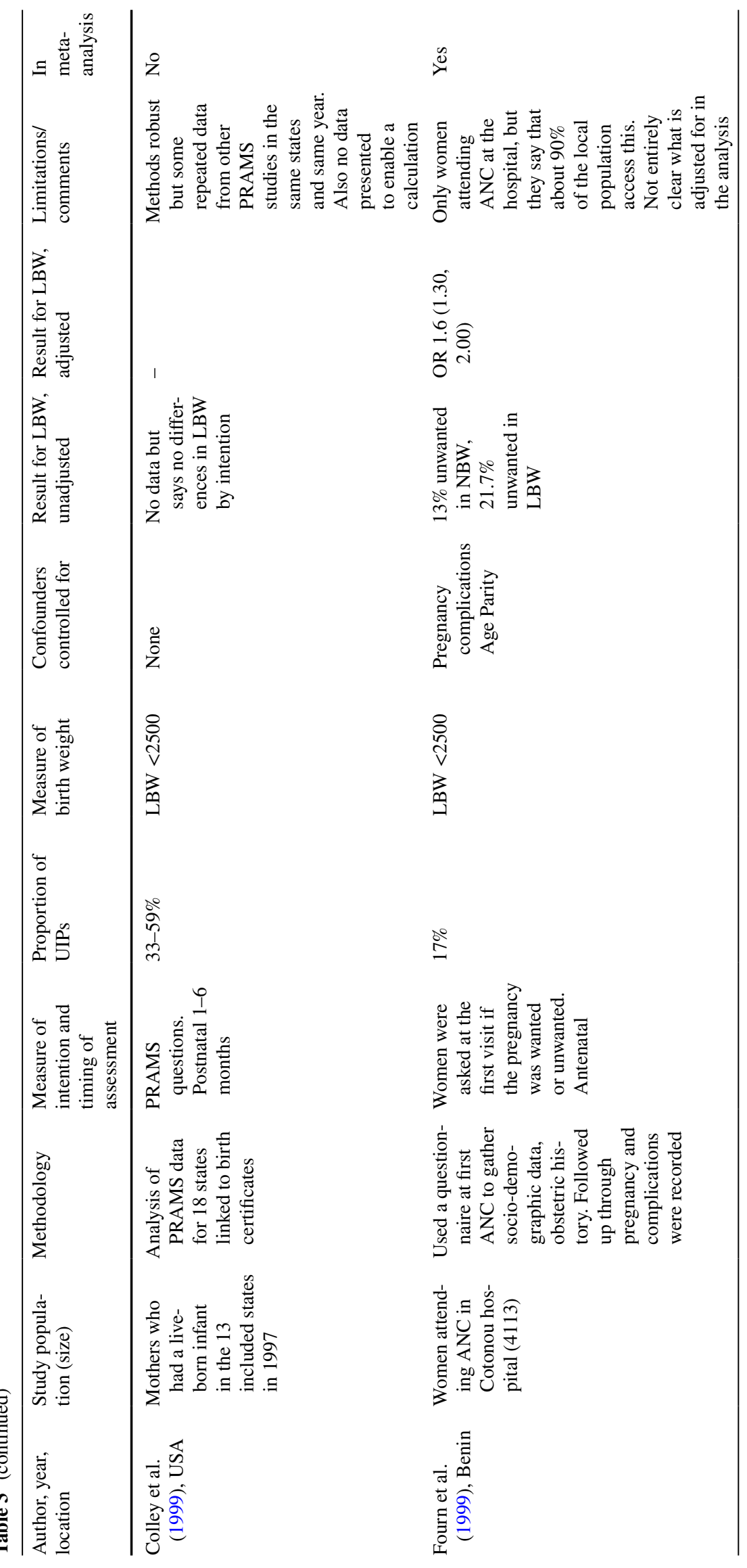




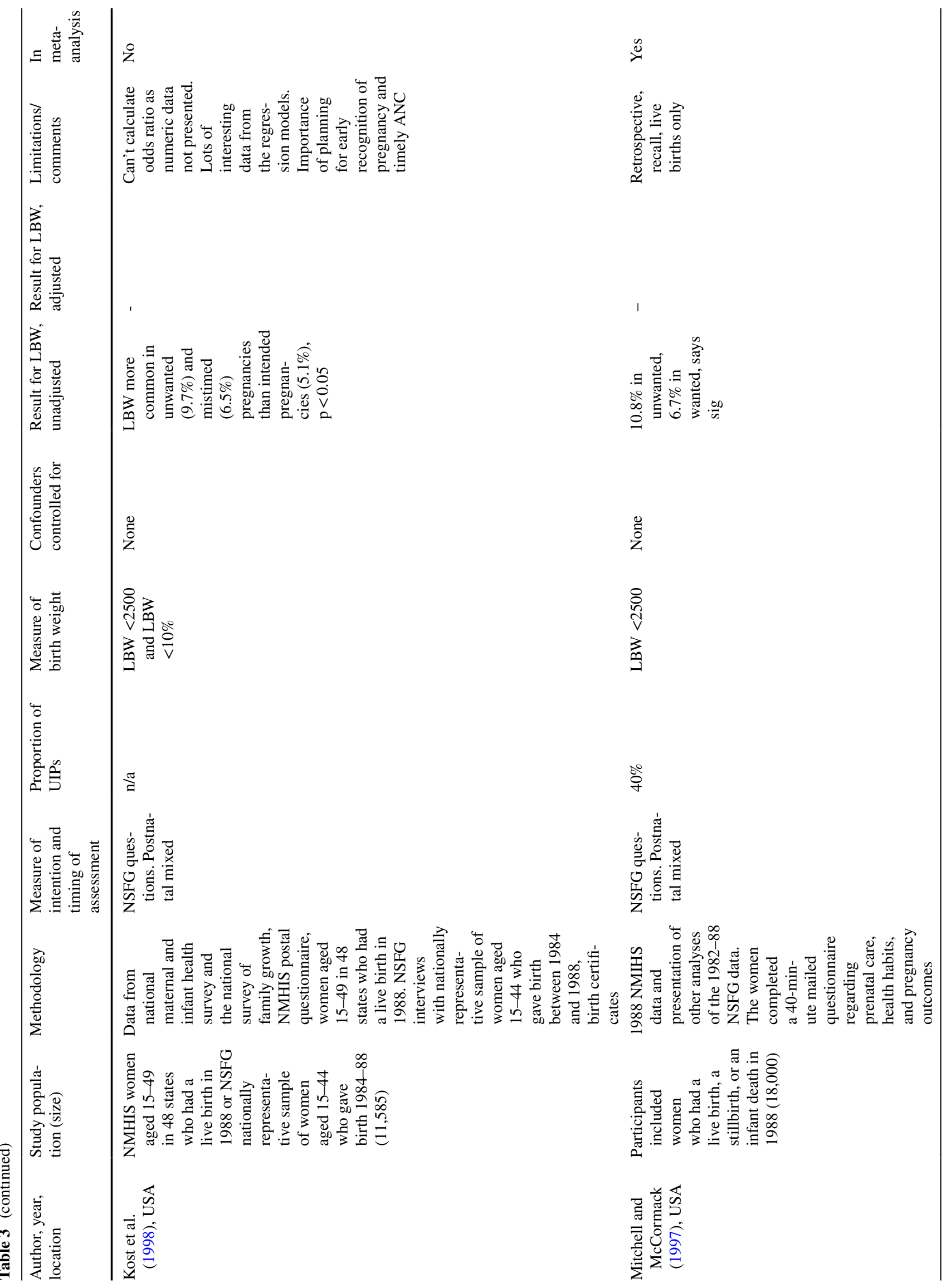




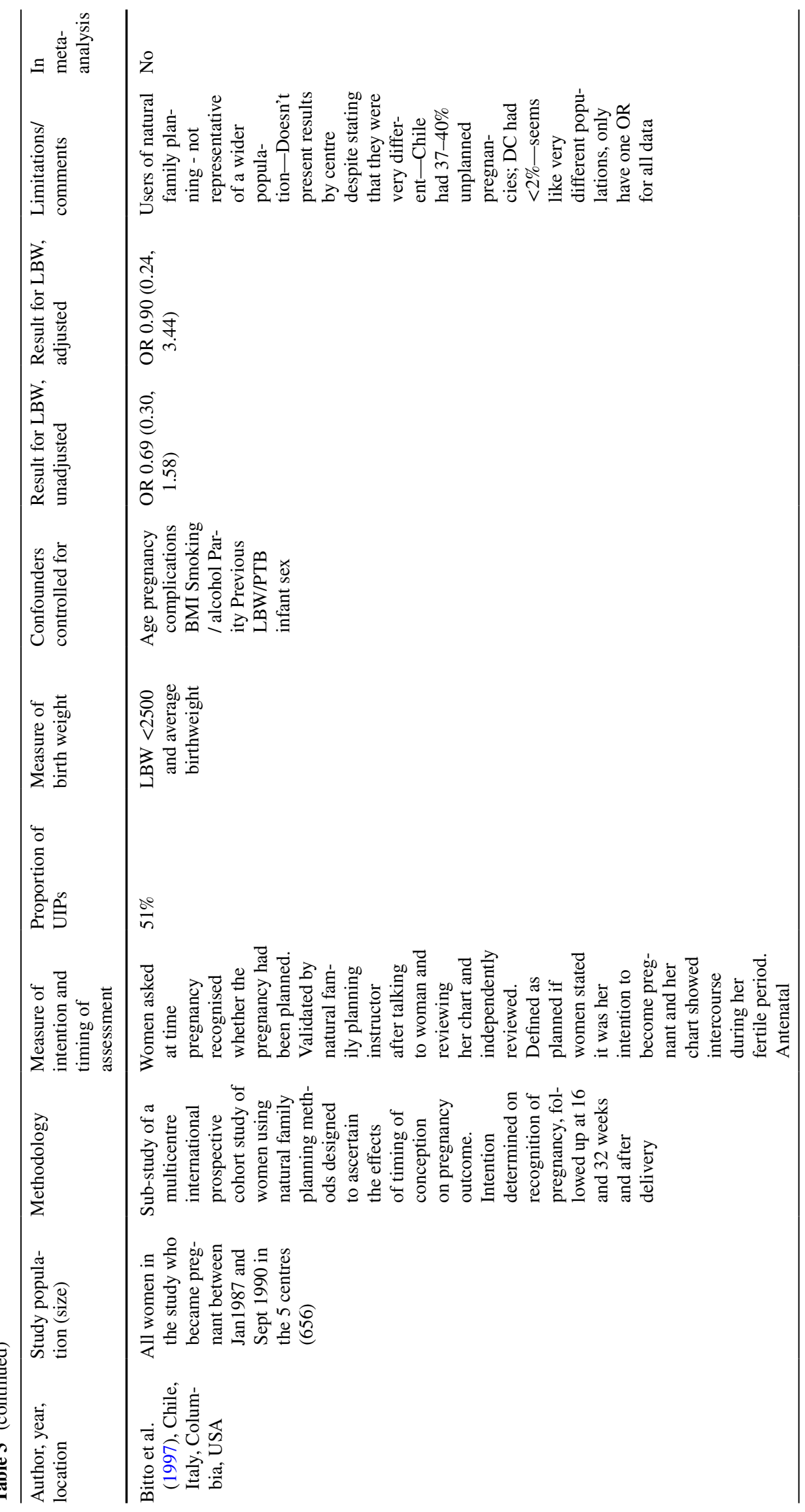




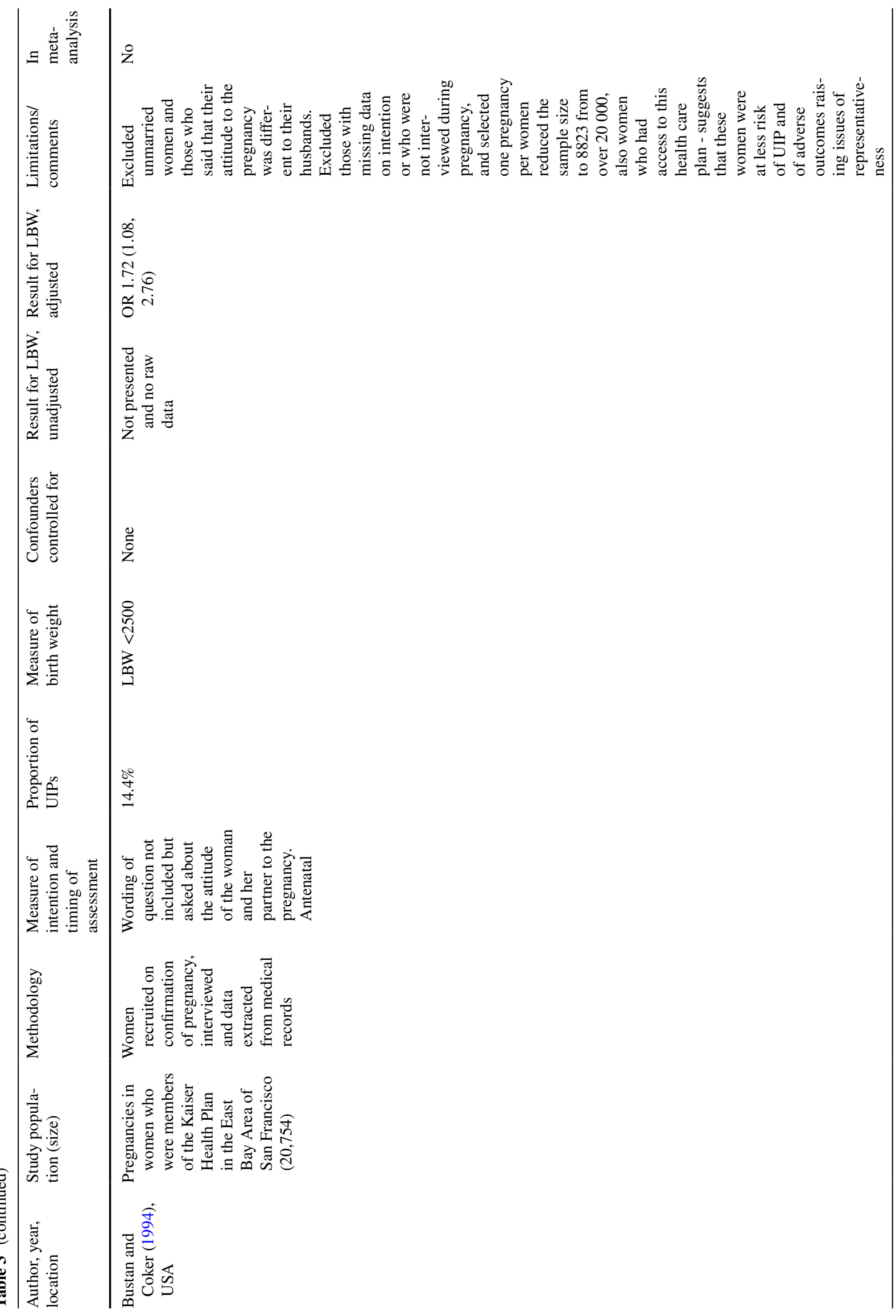




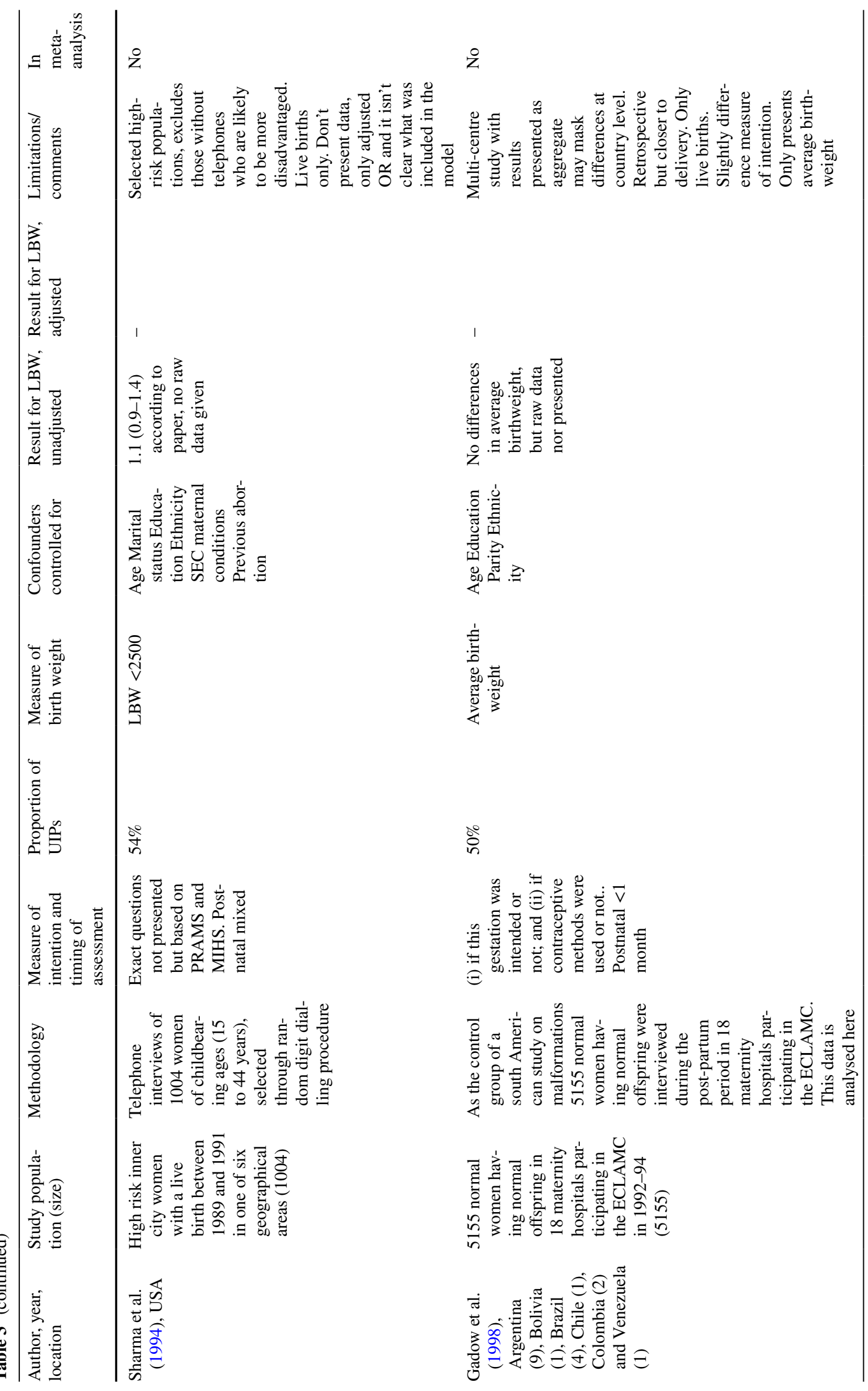




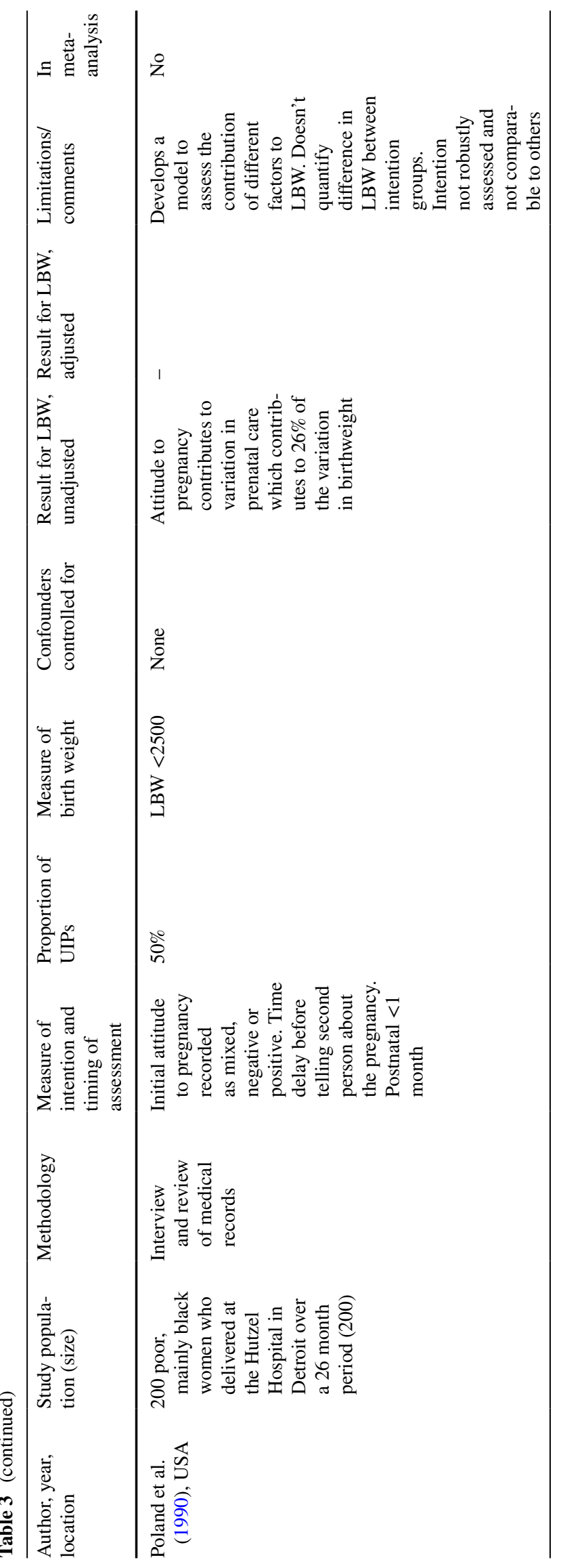




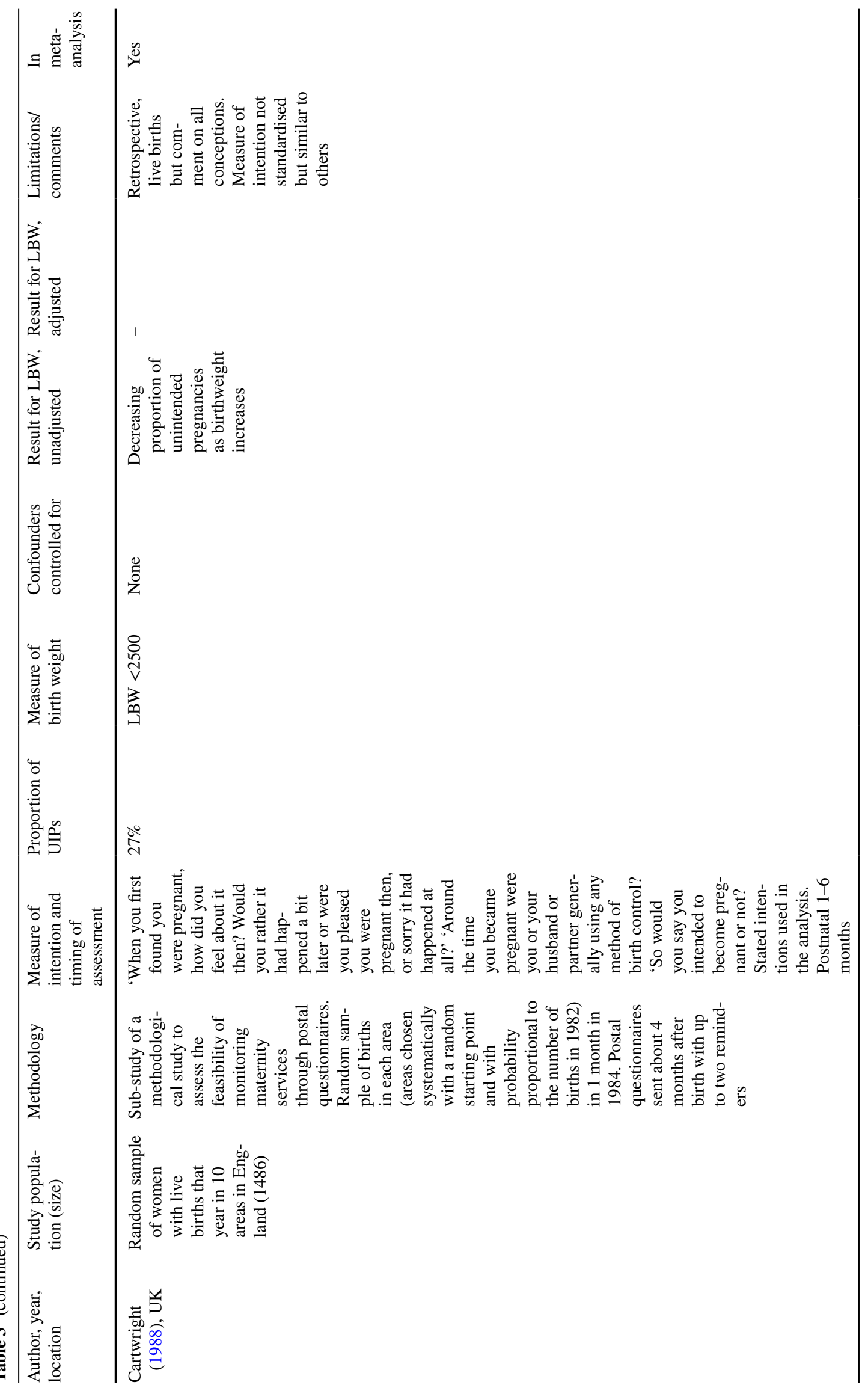




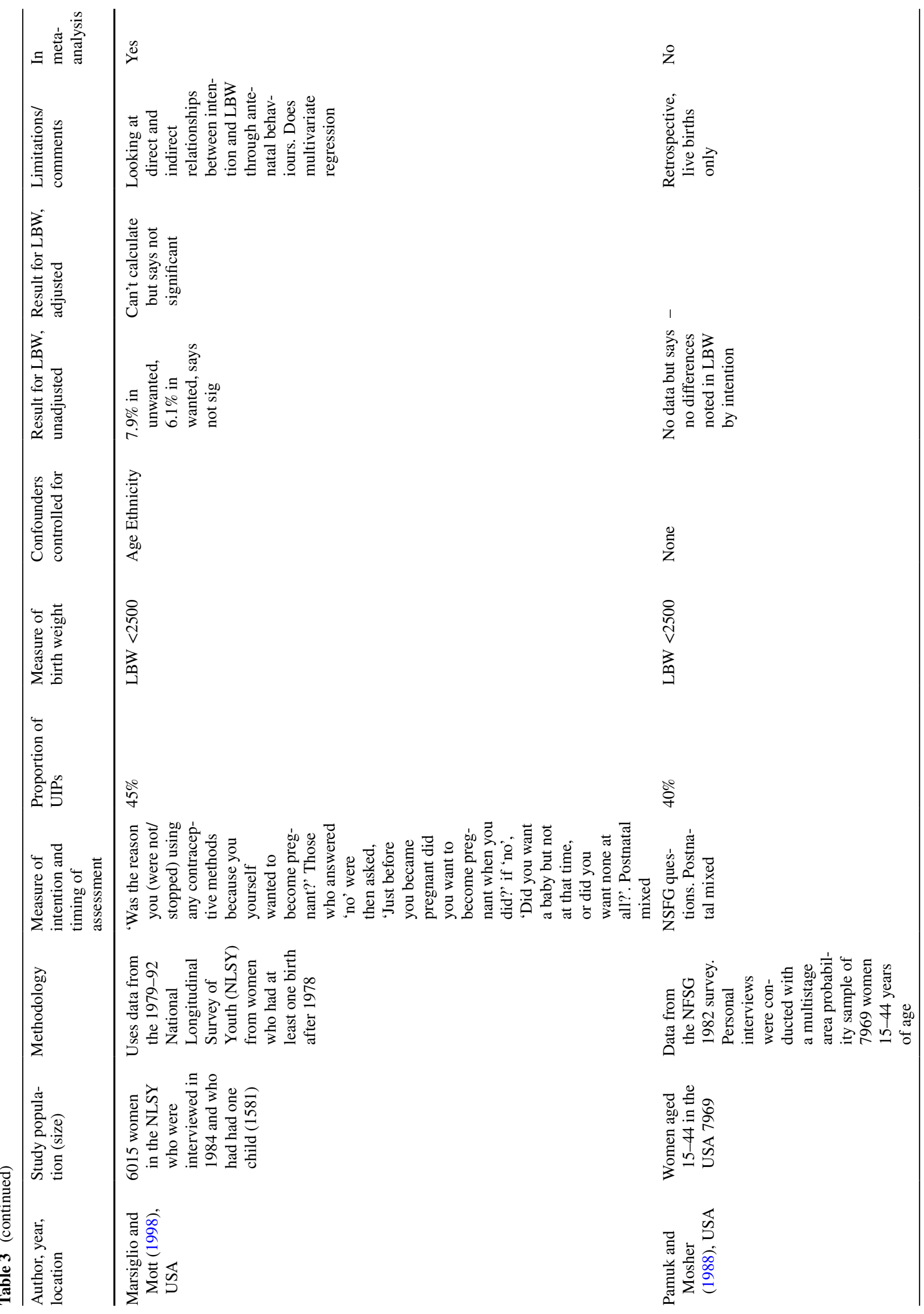




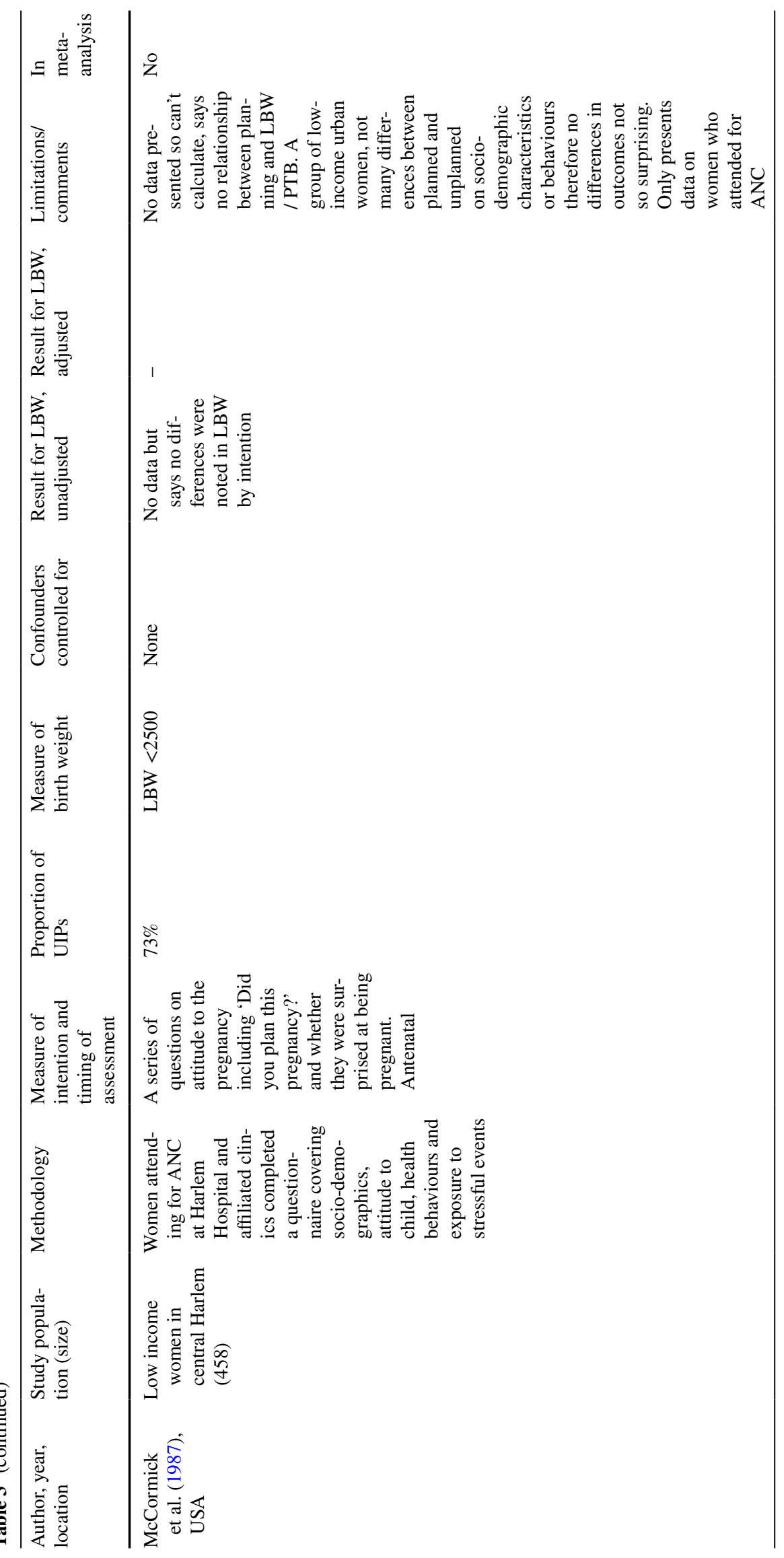




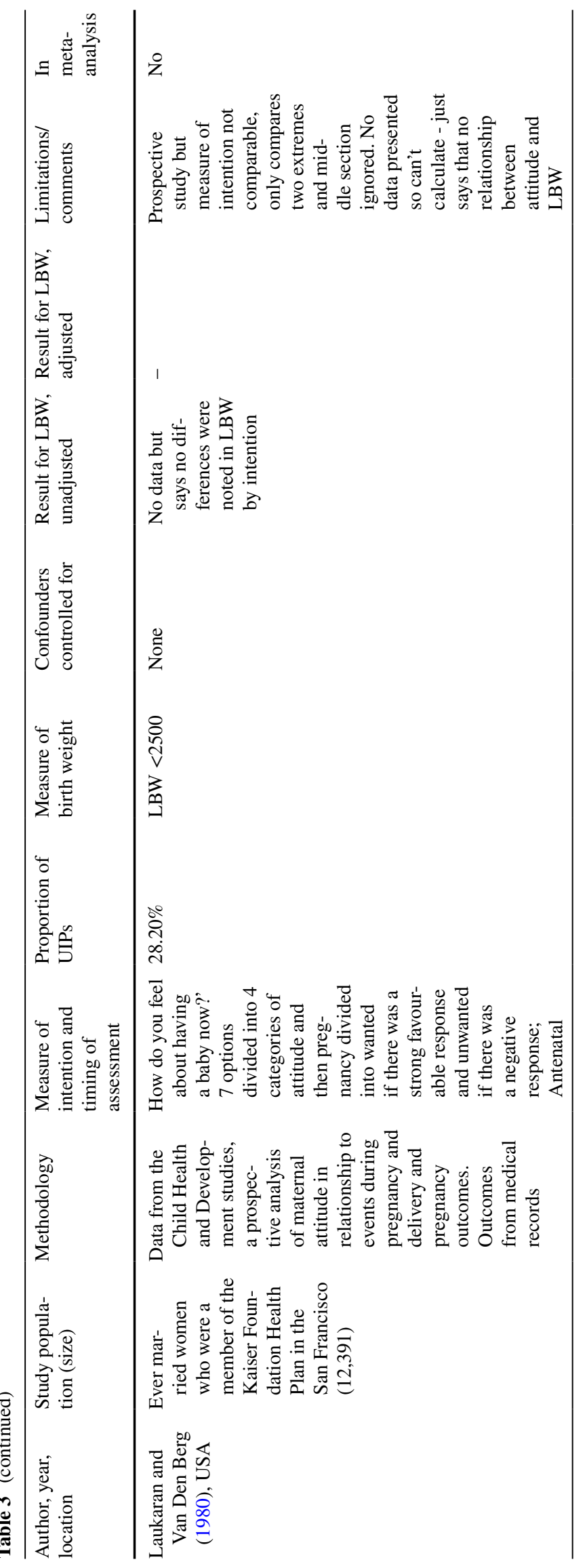




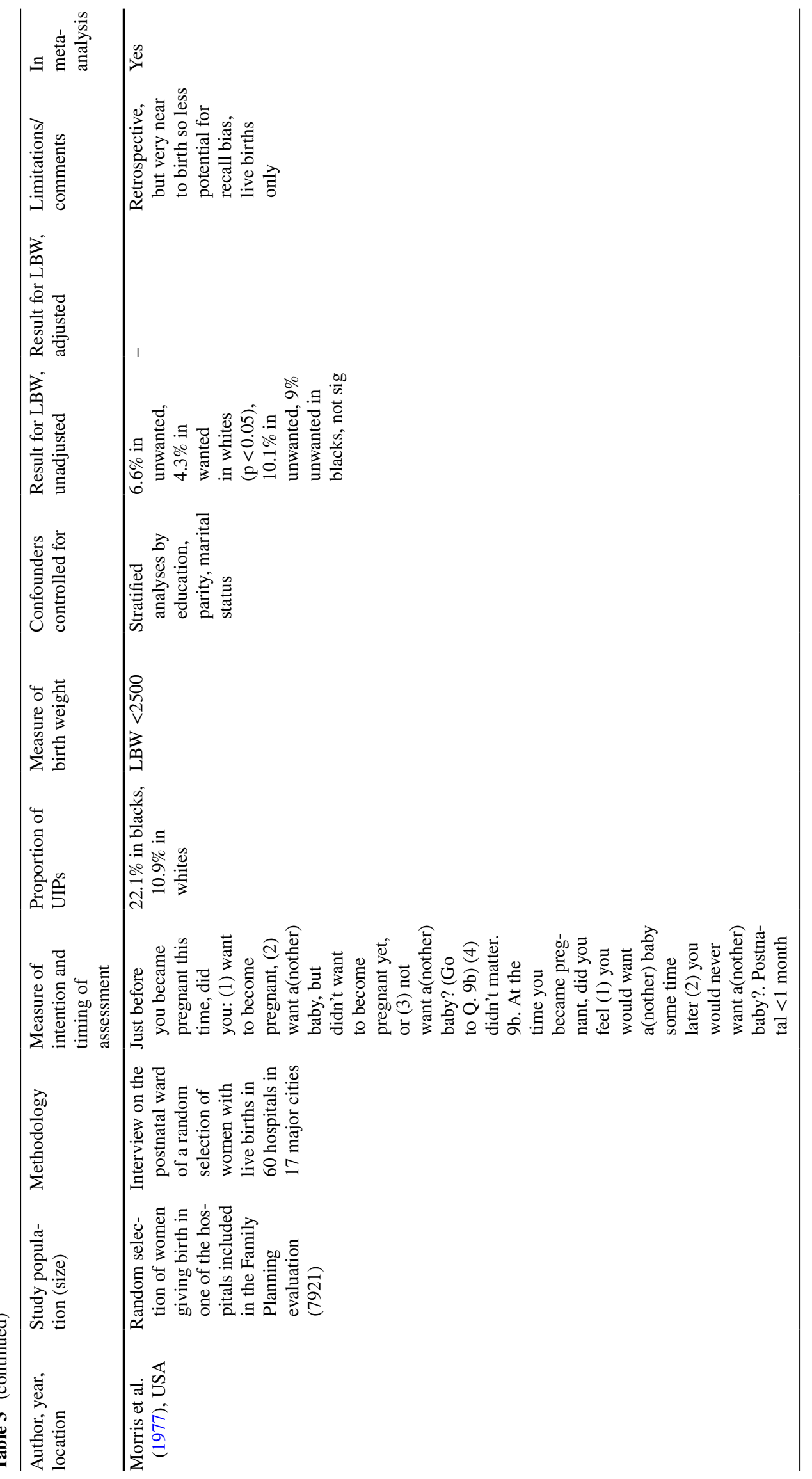



in the pregnancy intention and LBW meta-analysis
Fig. 2 Flow chart of the studies

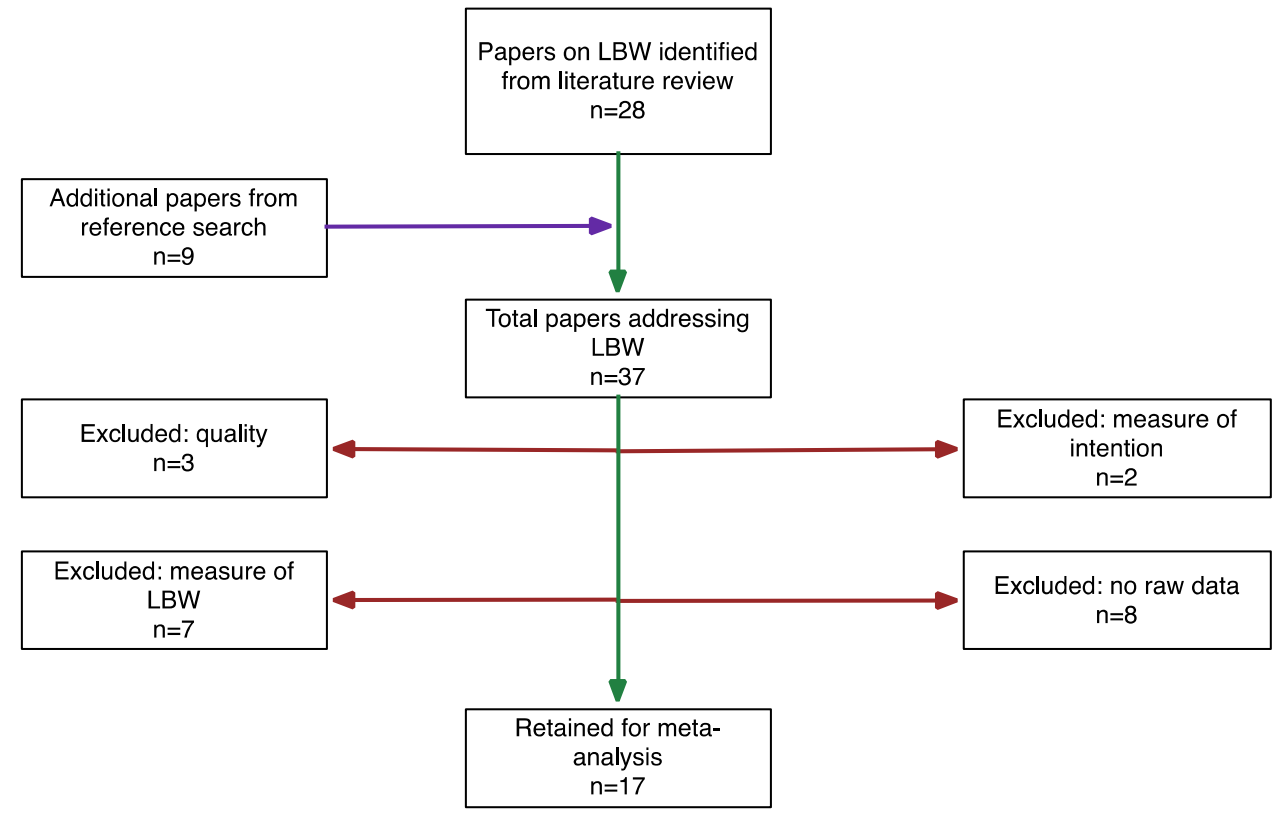

Random effects meta-analysis of pregnancy intention and LBW

Fig. 3 Forest plot of the random effects meta-analysis of studies assessing the relationship between pregnancy intention and LBW

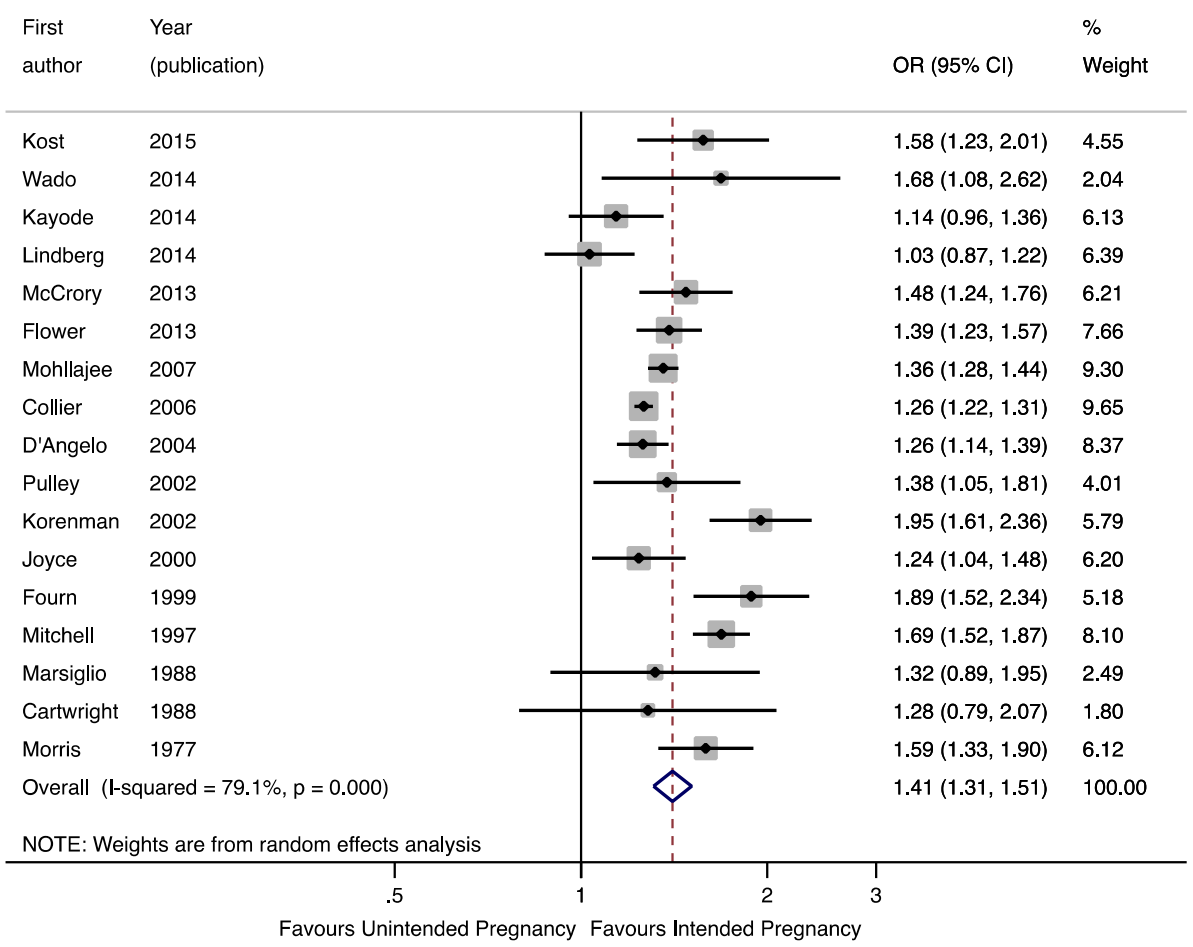

Odds ratio of pregnancy intention, though with the limited data available from either LICs or prospective studies this is not certain.

There are varying amounts of data for the relationships between pregnancy intention and pregnancy outcomes.
There is a suggestion that pregnancy loss may be higher in unintended pregnancies in LICs and that unintended pregnancies are associated with increased neonatal mortality in both HICs and LICs after adjusting for confounders. However, there are limited data in this area and there is no 
Fig. 4 Forest plot of the random effects meta-analysis of studies assessing the relationship between pregnancy intention and LBW stratified by location
Random effects meta-analysis of pregnancy intention and LBW by location

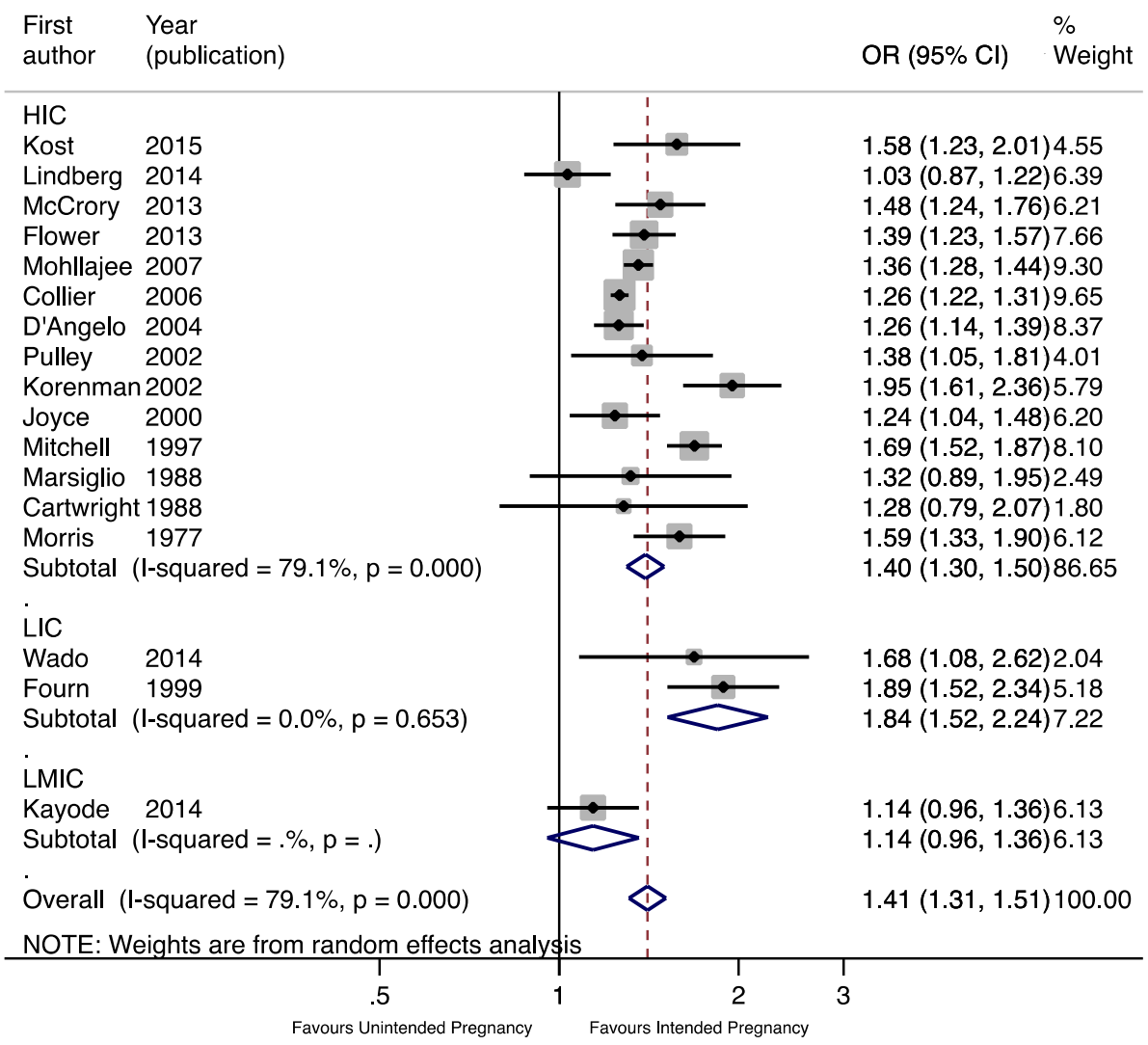

Odds ratio exploration of the mechanism of effect, whether through biological studies, psychosocial stress or uptake of services.

Despite much academic debate around the construct and measurement of pregnancy intention, this does not appear to have translated into methodologically improved research in this area; the methodological limitations highlighted by Tsui et al. (2010) persist. Studies continue to be dominated by cross-sectional, retrospective surveys where pregnancies are dichotomised into intended or unintended on the basis of a single question. The various questions used, whether asking about timing, desire or happiness, are all assumed to be measuring the same construct, despite evidence to the contrary (Trussell et al. 1999). Some studies have begun to disaggregate unintended pregnancies into mistimed and unwanted during analysis and in doing so are uncovering differential effects and determinants, reinforcing the need for a more refined measure of pregnancy intention (Mohllajee et al. 2007; Shah et al. 2011; Wado et al. 2014). To date very few studies have assessed pregnancy intention using a psychometrically validated measure, and none of the LBW studies in this review had, which could be one reason for the inconsistencies seen between studies.
Furthermore, the effect of pregnancy intention on pregnancy outcomes is likely to be confounded or mediated by a number of other factors. The determinants of pregnancy intention are often the same as the risk factors for adverse outcomes. For instance, a fourth or subsequent pregnancy is both more likely to be unintended (Bustan and Coker 1994; Flower et al. 2013; Mohllajee et al. 2007) and to have an adverse outcome (Bai et al. 2002). In addition, pregnancy intention and some of its determinants are related to lower uptake of preventative care practices during the antenatal, intra-partum and postnatal periods and to higher levels of risky behaviours during pregnancy, which are also known to increase the risk of adverse outcomes (Lindberg et al. 2014; Marston and Cleland 2003; Mohllajee et al. 2007; Shaheen et al. 2007). However, most studies have not sufficiently accounted for this in their analyses. There is some suggestion from adjusted analyses of papers included in this review that confounders or mediators, such as socioeconomic status, smoking (in HICs), maternal nutrition and uptake of antenatal care, may explain the effect of pregnancy intention on increased risk of LBW (McCrory and McNally 2013; Mohllajee et al. 2007; Wado et al. 2014). 
Fig. 5 Forest plot of the random effects meta-analysis of studies assessing the relationship between pregnancy intention and LBW stratified by timing of assessment of intention
Random effects meta-analysis of pregnancy intention and LBW by timing of intention assessment

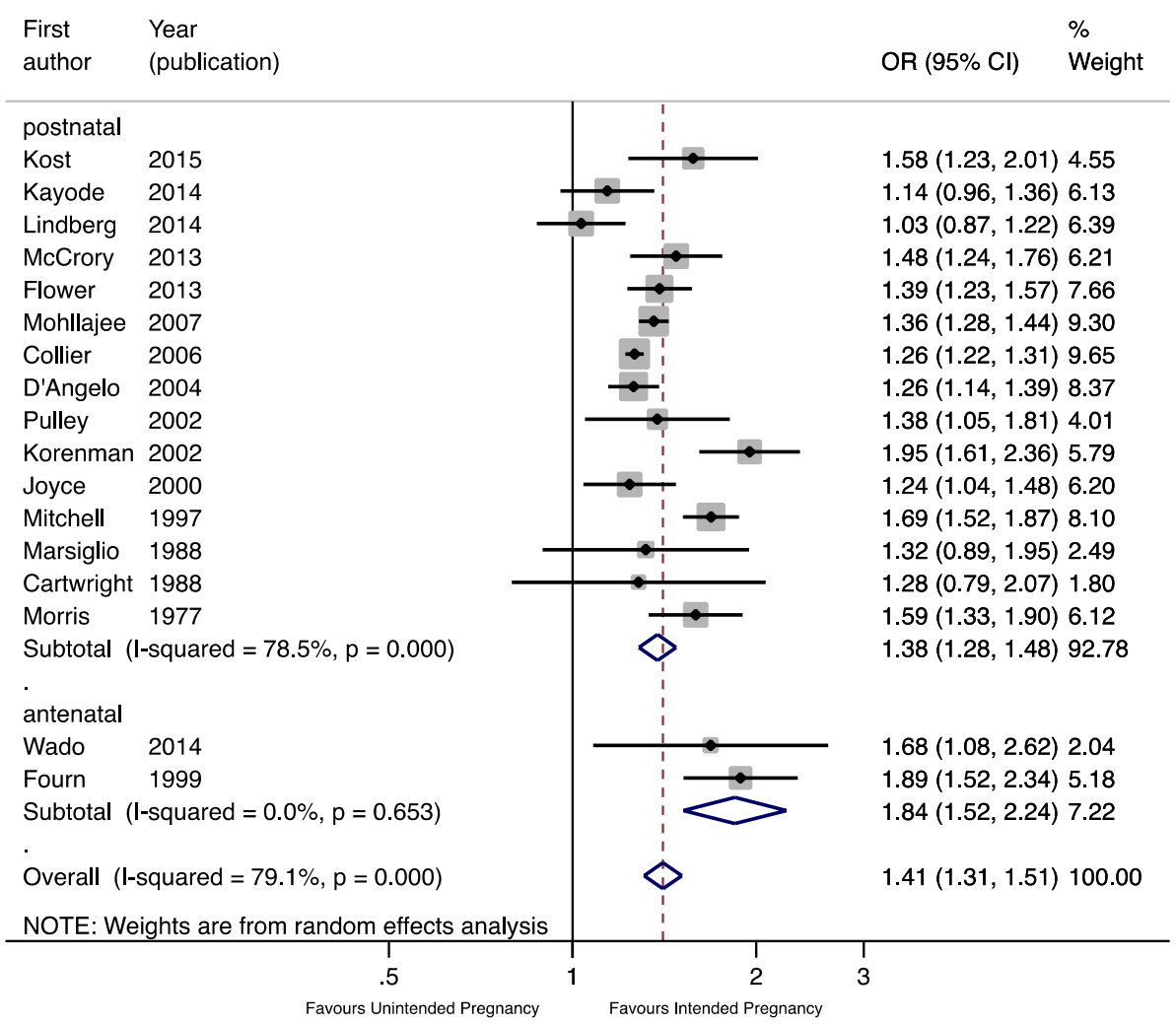

Odds ratio

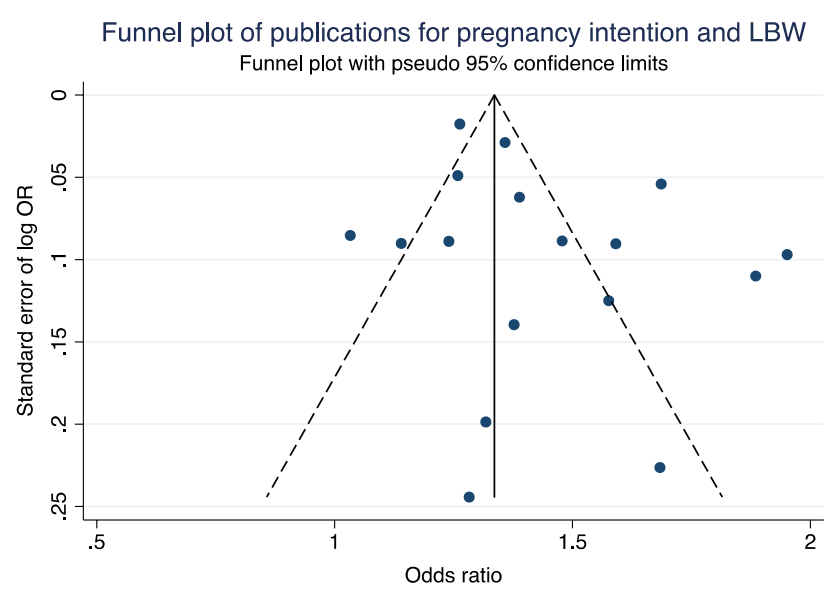

Fig. 6 Funnel plot for pregnancy intention and LBW

\section{Limitations}

There are two main limitations to this review. Firstly, the searches were only conducted on databases and therefore did not include unpublished studies, the grey literature or consultation with experts. This could mean that relevant studies were missed; nevertheless we identified more studies than previous reviews in these areas had. Shah et al. (2011), for example, only identified ten studies on low birth weight. Secondly, we did not contact authors to obtain raw data if it had not been presented in the study. This meant that some eligible studies could not be included in the analysis and seemed to be more likely to occur when studies found no relationship. This could lead to an over-estimate of the relationships between pregnancy intentions and outcomes. Furthermore we did not seek to obtain individual participant data that would have allowed a more detailed and coherent meta-analysis.

\section{Conclusion}

This review has highlighted persistent gaps and flaws with the existing evidence. The general lack of studies in developing countries noted by Gipson et al. (2008) persists, though there have been more studies in these areas over the last few years. These studies have tended to find a greater risk of adverse outcomes with unintended pregnancy.

Current evidence suggests that there may be a relationship between pregnancy intention and pregnancy outcome. To confirm this, and to understand how this relationship 
is mediated, longitudinal studies are required. Pregnancy intention should be measured before birth and data on the potential confounders and mediators, including maternal background characteristics, pre-conception, antenatal, delivery and postnatal behaviours, should be collected. A psychometrically valid measure of pregnancy intention that assesses intention on a continuous scale, such as the London Measure of Unplanned Pregnancy (Barrett et al. 2004), should be used in preference to dichotomous measures and the full range of scores should be used in the analysis. A better understanding of the way in which pregnancy intention influences pregnancy outcome will enable us to tailor pre-conception, antenatal, delivery and postnatal services to meet women's needs and reduce the risk of adverse outcomes. While these methodological advances are required in research in high-income countries, research in low-income countries, where arguably the consequences of unintended pregnancies are much greater, is urgently needed.
Acknowledgements This study was funded by a three-year personal Research Training Fellowship from the Wellcome Trust to Dr J Hall, award number 097268/Z/11/Z.

\section{Compliance with Ethical Standards}

Conflict of interest The authors declare that they have no conflict of interest.

Open Access This article is distributed under the terms of the Creative Commons Attribution 4.0 International License (http:// creativecommons.org/licenses/by/4.0/), which permits unrestricted use, distribution, and reproduction in any medium, provided you give appropriate credit to the original author(s) and the source, provide a link to the Creative Commons license, and indicate if changes were made.

\section{Appendix}

\section{See Table 4.}

Table 4 Wording of questions to assess pregnancy intention

Survey name Pregnancy intention questions on survey

National Survey of Family Growth 1. Was the reason you (were not/stopped) using any method because you, yourself, wanted to become preg(NSFG) from 1973, 1976, 1982, nant? (Yes/No - If yes, go to Q4, If no, go to Q2)

$1988,1995,2002,2006-10$ and 2 . At the time you became pregnant, did you, yourself, actually want to have a(nother) baby at some time? 2011-13. USA

(Yes/No/Don't know - If yes, go to Q4, If no, go to Q5, if don't know, go to Q3)

3. It is sometimes difficult to recall these things, but, as you look back to just before that pregnancy began, would you say you probably wanted a(nother) baby at some time or probably not? (If probably yes, go to Q4, if probably no or didn't care, go to Q5)

4. Did you become pregnant sooner than you wanted, later than you wanted, or at about the right time? (Sooner/ later/right time/didn't care)

5. And what about your partner at the time you became pregnant... did he want you to have a(nother) baby at some time? (Yes/no/don't know - If yes, go to Q6)

6. Did you become pregnant sooner than he wanted, later than he wanted, or at about the right time? (Sooner/later/ right time/didn't care)

Additional questions used in 1995 survey

(For all women) Which number on the card best describes how you felt when you found out you were pregnant? (Card has a 10-point scale from 1-very unhappy to 10-very happy)

(For women under 25) Which number on the card best describes your opinion about becoming pregnant? (Card has a 10-point scale from 1 strongly disagree to 10 - strongly agree)

You were worried that you did not know enough about how to take care of a baby

You thought that a new baby would keep you from doing the things that you were used to doing like working, going to school, going out and so on

You looked forward to teaching and caring for a new baby

You looked forward to the new experiences that having a baby would bring

You looked forward to experiencing the changes in your body that come with carrying a baby

You looked forward to telling your friends that you were pregnant

You were worried about what being pregnant would do to your body

You were worried that you did not have enough money to take care of a baby

You dreaded telling your friends that you were pregnant

You looked forward to buying things for a new baby

Pregnancy Risk Assessment Monitoring System (PRAMS) from 1987 to date. USA

Demographic and Health Survey
1. Thinking back to just before you were pregnant, how did you feel about becoming pregnant?

a. I wanted to be pregnant sooner

b. I wanted to be pregnant then

c. I wanted to be pregnant later

d. I didn't want to be pregnant then or at any time in the future

At the time you became pregnant did you want to become pregnant then, did you want to wait until later, or did you want to have no (more) children at all? 


\section{References}

Ahluwalia, I., Merritt, R., Beck, L., \& Rogers, M. (2001). Multiple lifestyle and psychosocial risks and delivery of small for gestational age infants. Obstet Gynecol, 97(5 Pt 1), 649-656.

Assefa, N., Berhane, Y., Worku, A., \& Tsui, A. (2012). The hazard of pregnancy loss and stillbirth among women in Kersa, East Ethiopia: A follow up study. Sexual and Reproductive Healthcare, 3(3), 107-112.

Bai, J., Wong, F. W., Bauman, A., \& Mohsin, M. (2002). Parity and pregnancy outcomes. American Journal of Obstetrics and Gynecology, 186(2), 274-278.

Barrett, G., Smith, S., \& Wellings, K. (2004). Conceptualisation, development and evaluation of a measure of unplanned pregnancy. Journal of Epidemiology and Community Health, 58, 426-433.

Bitto, A., Gray, R. H., Simpson, J. L., Queenan, J. T., Kambic, R. T., Perez, A., ... Jennings, V. (1997). Adverse outcomes of planned and unplanned pregnancies among users of natural family planning: A prospective study. American Journal of Public Health, 87(3), 338-343.

Bustan, M. N., \& Coker, A. L. (1994). Maternal attitude toward pregnancy and the risk of neonatal death. American Journal of Public Health, 84(3), 411-414.

Cartwright, A. (1988). Unintended pregnancies that lead to babies. Social Science and Medicine, 27(3), 249-254.

Chalansani, S., Casterline, J., \& Koenig, M. (2007). Consequences of unwanted childbearing: a study of child outcomes in Bangladesh. Paper presented at the Annual Meeting of the Population Association of America, New York.

Colley Gilbert, B. J., Johnson, C. H., Morrow, B., Gaffield, M. E., \& Ahluwalia, I. (1999). Prevalence of selected maternal and infant characteristics, Pregnancy Risk Assessment Monitoring System (PRAMS), 1997. MMWR, CDC surveillance summaries : Morbidity and mortality weekly report. CDC surveillance summaries /. Centers for Disease Control, 48(5), 1-37.

Collier, S. A., \& Hogue, C. J. R. (2007). Modifiable risk factors for low birth weight and their effect on cerebral palsy and mental retardation. Maternal and Child Health Journal, 11(1), 65-71.

D’Angelo, D. V., Gilbert, B. C., Rochat, R. W., Santelli, J. S., \& Herold, J. M. (2004). Differences between mistimed and unwanted pregnancies among women who have lives births. Perspectives on Sexual and Reproductive Health, 36(5), 192-197.

Dawen, Y., Tan, T. L., \& Wang, H. (2014). Is unplanned pregnancy associated with pregnancy loss? BJOG: An International Journal of Obstetrics and Gynaecology, 121, 13.

Durousseau, S., \& Chavez, G. F. (2003). Associations of intrauterine growth restriction among term infants and maternal pregnancy intendedness, initial happiness about being pregnant, and sense of control. Pediatrics, 111(5 II), 1171-1175.

Eggleston, E., Tsui, A. O., \& Kotelchuck, M. (2001). Unintended pregnancy and low birthweight in Ecuador. American Journal of Public Health, 91(5), 808-810.

Flores, M., Schwarz, E. B., Manuck, T. A., Jacobson, J., Simonsen, S. E., \& Turok, D. K. (2010). Risk factors for and consequences of unintended pregnancy among Latina and white populations in Utah, 2004-2007. Contraception, 82(2), 213.

Flower, A., Shawe, J., Stephenson, J., \& Doyle, P. (2013). Pregnancy planning, smoking behaviour during pregnancy, and neonatal outcome: UK millennium cohort study. BMC Pregnancy and Childbirth, 13(238).

Fourn, L., Ducic, S., \& Séguin, L. (1999). Risk factors associated with low birth weight: A multivariate analysis. Cahiers Sante, 9(1), 7-11.
Gadow, E. C., Paz, J. E., Lopez-Camelo, J. S., Dutra, M. D. G., Queenan, J. T., Simpson, J. L., ... Castilla, E. E. (1998). Unintended pregnancies in women delivering at 18 South American hospitals. Human Reproduction, 13(7), 1991-1995.

Gipson, J. D., Koenig, M. A., \& Hindin, M. J. (2008). The effects of unintended pregnancy on infant, child, and parental health: A review of the literature. Studies in Family Planning, 39(1), 18-38. doi:10.1111/j.1728-4465.2008.00148.x.

Hohmann-Marriott, B. (2009). The couple context of pregnancy and its effects on prenatal care and birth outcomes. Maternal and Child Health Journal, 13(6), 745-754.

Iranfar, S., Iranfar, K., \& Ranjbar, M. (2009). Is there any relationship between neonatal babies weight and unintended pregnancy? Pakistan Journal of Medical Sciences, 25(5), 841-844.

Joyce, T. J., Kaestner, R., \& Korenman, S. (2000). The effect of pregnancy intention on child development. Demography, 37(1), 83-94.

Kayode, G. A., Amoakoh-Coleman, M., Akua Agyepong, I., Ansah, E., Grobbee, D. E., \& Klipstein-Grobusch, K. (2014). Contextual risk factors for low birth weight: A multilevel analysis. PLoS ONE, 9(10).

Korenman, S., Kaestner, R., \& Joyce, T. (2002). Consequences for infants of parental disagreement in pregnancy intention. Perspectives on Sexual and Reproductive Health, 34(4), 198-205. doi:10.2307/3097730.

Kost, K., Landry, D. J., \& Darroch, J. E. (1998). The effects of pregnancy planning status on birth outcomes and infant care. Family Planning Perspectives, 30(5), 223-230.

Kost, K., \& Lindberg, L. (2015). Pregnancy Intentions, Maternal Behaviors, and Infant Health: Investigating Relationships With New Measures and Propensity Score Analysis. Demography. doi:10.1007/s13524-014-0359-9.

Laukaran, V. H., \& Van Den Berg, B. J. (1980). The relationship of maternal attitude to pregnancy outcomes and obstetric complications. A cohort study of unwanted pregnancy. American Journal of Obstetrics and Gynecology, 136(3), 374-379.

Lindberg, L., Maddow-Zimet, I., Kost, K., \& Lincoln, A. (2014). Pregnancy Intentions and Maternal and Child Health: An Analysis of Longitudinal Data in Oklahoma. Maternal and Child Health Journal. doi:10.1007/s10995-014-1609-6.

Marsiglio, W., \& Mott, F. (1998). Does wanting to become pregnant with a first child affect subsequent maternal behaviors and infant birth weight? Journal of Marriage and Family, 50(4), $1-23-1036$.

Marston, C., \& Cleland, J. (2003). Do unintended pregnancies carried to term lead to adverse outcomes for mother and child? An assessment in five developing countries. Population Studies, 57(1), 77-93. doi:10.1080/0032472032000061749.

McCormick, M. C., Brooks-Gunn, J., Shorter, T., Wallace, C. Y., Holmes, J. H., \& Heagarty, M. C. (1987). The planning of pregnancy among low-income women in central Harlem. American Journal of Obstetrics and Gynecology, 156(1), 145149. doi:10.1016/0002-9378(87)90226-2.

McCrory, C., \& McNally, S. (2013). The effect of pregnancy intention on maternal prenatal behaviours and parent and child health: Results of an Irish cohort study. Paediatric and Perinatal Epidemiology, 27(2), 208-215.

Mitchell, J. B., \& McCormack, L. A. (1997). Access to family planning services: relationship with unintended pregnancies and prenatal outcomes. Journal of health care for the poor and underserved, 8(2), 141-152.

Mohllajee, A. P., Curtis, K. M., Morrow, B., \& Marchbanks, P. A. (2007). Pregnancy intention and its relationship to birth and maternal outcomes. Obstetrics and Gynecology, 109(3), 678-686. 
Morris, N. M., Udry, J. R., \& Chase, C. L. (1977). Reduction of low birth weight rates by the prevention of unwanted pregnancies. Family Planning Resume, 1(1), 252-253.

Pamuk, E. R., \& Mosher, W. D. (1988). Health aspects of pregnancy and childbirth. Vital and Health Statistics. Series 23, No 16. DHHS Pub. No. (PHS) 89-1992 Public Health Service. Washington: US Government Printing Office.

Poland, M. L., Ager, J. W., Olson, K. L., \& Sokol, R. J. (1990). Quality of prenatal care; selected social, behavioral, and biomedical factors; and birth weight. Obstetrics and gynecology, 75(4), 607-612.

Postlethwaite, D., Armstrong, M. A., Hung, Y. Y., \& Shaber, R. (2010). Pregnancy outcomes by pregnancy intention in a managed care setting. Maternal and Child Health Journal, 14(2), 227-234.

Pulley, L., Klerman, L., Tang, H., \& Baker, B. (2002). The extent of pregnancy mistiming and its association with maternal characteristics and behaviors and pregnancy outcomes. Perspectives on Sexual and Reproductive Health, 34(4), 206-211.

Rafati, S., Borna, H., Akhavirad, M. B., \& Fallah, N. (2005). Maternal determinants of giving birth to low-birth-weight neonates. Archives of Iranian Medicine, 8(4), 277-281.

Sable, M. R., \& Wilkinson, D. S. (2000). Impact of perceived stress, major life events and pregnancy attitudes on low birth weight. Family Planning Perspectives, 32(6), 288-294.

Saedi, R., Ahmadian, M., Ghalibaf, M. B., \& Hashemian, M. (2013). Survey on correlation between unplan pregnancy and low birth weight in new infants. Iranian Journal of Neonatology, 4(2), 26-33.

Shah, P. S., Balkhair, T., Ohlsson, A., Beyene, J., Scott, F., \& Frick, C. (2011). Intention to become pregnant and low birth weight and preterm birth: a systematic review. Maternal and Child Health Journal, 15(2), 205-216.

Shaheen, A. A., Diaaeldin, M., Chaaya, M., \& El Roueiheb, Z. (2007). Unintended pregnancy in Egypt: Evidence from the national study on women giving birth in 1999. Eastern Mediterranean Health Journal, 13(6), 1392-1404.
Sharma, R., Synkewecz, C., Raggio, T., \& Mattison, D. R. (1994). Intermediate variables as determinants of adverse pregnancy outcome in high-risk inner-city populations. Journal of the National Medical Association, 86(11), 857-860.

Singh, A., Chalasani, S., Koenig, M. A., \& Mahapatra, B. (2012). The consequences of unintended births for maternal and child health in India. Population Studies, 66(3), 223-239. doi:10.1080/00324 728.2012 .697568 .

Singh, A., \& Mahapatra, B. (2013). The consequences of unintended pregnancy for maternal and child health in rural India: Evidence from prospective data. Maternal and Child Health Journal, 17(3), 493-500.

Stroup, D. F., Berlin, J. A., Morton, S. C., Olkin, I., Williamson, G. D., Rennie, D., ... Thacker, S. B. (2000). Meta-analysis of observational studies in epidemiology: a proposal for reporting. Metaanalysis Of Observational Studies in Epidemiology (MOOSE) group. Journal of the American Medical Academy, 283(15), 2008-2012.

Trussell, J., Vaughan, B., \& Stanford, J. (1999). Are all contraceptive failures unintended pregnancies? Evidence from the 1995 National Survey of Family Growth. Fam Plann Perspect, 31(5), 246-247.

Tsui, A. O., McDonald-Mosley, R., \& Burke, A. E. (2010). Family planning and the burden of unintended pregnancies. Epidemiologic Reviews, 32(1), 152-174. doi:10.1093/epirev/mxq012.

Wado, Y. D., Afework, M. F., \& Hindin, M. J. (2014). Effects of maternal pregnancy intention, depressive symptoms and social support on risk of low birth weight: A prospective study from Southwestern Ethiopia. PLOS ONE, 9(5).

Wellings, K., Jones, K. G., Mercer, C. H., Tanton, C., Clifton, S., Datta, J., ... Johnson, \& A, M. (2013). The prevalence of unplanned pregnancy and associated factors in Britain: findings from the third National Survey of Sexual Attitudes and Lifestyles (Natsal-3). Lancet, 382(9907), 1807-1816. doi:10.1016/ S0140-6736(13)62071-1. 